\title{
Geospatial View of Air Pollution and Health Risk Over North Indian Region in COVID-19 Scenario
}

\author{
Dharmendra Singh $^{1}$ (D) $\cdot$ Meenakshi Dahiya ${ }^{1} \cdot$ Chintan Nanda ${ }^{1}$
}

Received: 4 May 2021 / Accepted: 2 February 2022 / Published online: 24 February 2022

(C) Indian Society of Remote Sensing 2022

\begin{abstract}
Air pollutant concentration, air quality index (AQI), and Excess risk (ER\%) is assessed during January 2020 to June 2021 and in three scenarios including pre-lockdown, lockdown and post-lockdown based on 47 ground station data (during January 2020 to June 2020) distributed over northern part of India (including Delhi, Haryana, Punjab, part of Uttar Pradesh, and part of Rajasthan) using statistics and geographic information system (GIS) techniques. Daily and monthly variations of air pollutants (During January 2020 to June 2021) over the region showed a systematic pattern with high pollutant level during October and November while low during March, April (in dry period) and July-September (in wet period). In three scenarios viz. pre, during and post-lockdown the average concentration for $\mathrm{PM}_{2.5}$ was $71.1 \pm 45 \mu \mathrm{g} / \mathrm{m}^{3}, 39 \pm 20 \mu \mathrm{g} / \mathrm{m}^{3}$ and $40+17 \mu \mathrm{g} / \mathrm{m}^{3}$, for $\mathrm{PM}_{10}$ was $139 \pm 72 \mu \mathrm{g} / \mathrm{m}^{3}, 96 \pm 55 \mu \mathrm{g} / \mathrm{m}^{3}$ and $105 \pm 57 \mu \mathrm{g} / \mathrm{m}^{3}$, for $\mathrm{NO}_{2}$ was $28 \pm 21 \mu \mathrm{g} / \mathrm{m}^{3}$, $17 \pm 13 \mu \mathrm{g} / \mathrm{m}^{3}$ and $18 \pm 12 \mu \mathrm{g} / \mathrm{m}^{3}$, for $\mathrm{NH}_{3}$ was $33 \pm 24 \mu \mathrm{g} / \mathrm{m}^{3}, 25 \pm 18 \mu \mathrm{g} / \mathrm{m}^{3}$ and $29 \pm 22 \mu \mathrm{g} / \mathrm{m}^{3}$, for CO was $1 \pm 0.65 \mathrm{mg} / \mathrm{m}^{3}, 0.7 \pm 0.5 \mathrm{mg} / \mathrm{m}^{3}$, and $0.7 \pm 0.5 \mathrm{mg} / \mathrm{m}^{3}$, for $\mathrm{O}_{3}$ was $29 \pm 20 \mu \mathrm{g} / \mathrm{m}^{3}, 39 \pm 23 \mu \mathrm{g} / \mathrm{m}^{3}$ and $39 \pm 22 \mu \mathrm{g} /$ $\mathrm{m}^{3}$ and for $\mathrm{SO}_{2}$ was $14 \pm 11 \mu \mathrm{g} / \mathrm{m}^{3}, 14 \pm 12 \mu \mathrm{g} / \mathrm{m}^{3}$ and $12.5 \pm 8.9 \mu \mathrm{g} / \mathrm{m}^{3}$. Significant decrease in mean pollutants concentration, AQI and ER \% was observed in lockdown period amid COVID-19. $\mathrm{PM}_{2.5}, \mathrm{PM}_{10}, \mathrm{NO}_{2}, \mathrm{NH}_{3}$ and $\mathrm{CO}$ decreased by $46 \%, 31 \%, 39 \%, 24 \%$ and $34 \%$, respectively, in lockdown scenario as compared to the pre-lockdown scenario while the $\mathrm{O}_{3}$ get increased. A decrease of 39\% in AQI was observed as compared to pre-lockdown scenario; however, the difference was less when compared with post-lockdown scenario. The decrease in total ER\% was $60.36 \%$ over the study area due to improvement in air quality over the region amid COVID-19 lockdown. The meteorological conditions in 2020 were found consistent with respect to 2019 and very less influence was observed on the concentration of air pollutants (less $r^{2}$ among the pollutants and meteorological parameters).
\end{abstract}

Keywords COVID-19 Air quality $\cdot$ Excess health risk $\cdot$ North India $\cdot$ Criteria pollutants

\section{Introduction}

In these days world population is facing threat from the corona virus which is also known as COVID-19. Corona Virus causes respiratory illness such as severe acute respiratory syndrome (WHO, 2020). This has modified the anthropogenic activities across the world in terms of

Dharmendra Singh

dharmbaghe101@gmail.com

Meenakshi Dahiya

meenu.dahiya649@gmail.com

Chintan Nanda

chintann549@gmail.com

1 Haryana Space Applications Center (HARSAC), Hisar, Haryana, India reduced human movement, reduced vehicle emissions and reduction in industrial activities which showed reduced level (ranging from 10 to 50\%) of air pollution/pollutants across the Globe (Lal et al., 2020; Mahato et al., 2020; Muhammad et al., 2020; Sharma et al., 2020; Siddiqui et al., 2020; Singh \& Nanda et al., 2021c; Srivastava et al., 2020; Tobías et al., 2020). In China human activity reduced by $69.85 \%$ in 44 cities and which mediated Air Quality Index (AQI), Particulate Matter $2.5\left(\mathrm{PM}_{2.5}\right)$, Carbon Monoxide (CO) partially and Particulate Matter $10\left(\mathrm{PM}_{10}\right)$, Sulphur dioxide $\left(\mathrm{SO}_{2}\right)$ and Nitrogen dioxide $\left(\mathrm{NO}_{2}\right)$ completely (Bao \& Zhang, 2020). Transport, social activities, and consumption of oil has been attenuated distinctly (Filonchyk et al., 2020; Muhammad et al., 2020).

COVID-19 has caused millions of death worldwide (5,542,359 till 18 January 2022), since its first reported 
instance from the Wuhan city of the China (WHO, 2021). India is the 2nd largest populated country after China with high population density, along with limited health care facilities, faced high risk from pandemic COVID-19 in terms of deaths, economy, and health hazard. When affected patients were increased, Indian government took action to control the spread of COVID-19 in India and declared first countrywide lockdown for 21 days on 24 March 2020 after a complete curfew on 22 March, 2020 followed by further lockdown stages till 31st May 2020. Non-essential services like school, colleges, markets, shopping mall, offices and tourist place were banned completely while essential services (water, electricity department, bank, hospitals, pharmaceutical store, milk dairy, etc.) were allowed during lockdown (Sharma, 2020). The lockdown has significantly reduced the transportation, mobility, and industrial operations which resulted in to the reduced level of air pollutants and improvement in the air quality (Sharma et al., 2020; Siddiqui et al., 2020; Singh \& Nanda et al., 2021c; Srivastava et al., 2020; Sur et al., 2021)

The changes in the pattern and magnitude of anthropogenic activities amid COVID-19 lockdown have clear impact on air quality and recent pandemic, i.e. COVID-19 has shown the glimpses for the same (Bao \& Zhang, 2020; Bhawre, 2020; Dantas et al., 2020; Filonchyk et al., 2020; Kant et al., 2020; Lal et al., 2020; Nakada \& Urban, 2020; Otmani et al., 2020; Pathakoti et al., 2020; Ranjan et al., 2020; Sharma et al., 2020; Siddiqui et al., 2020; Singh \& Nanda et al., 2021c; Srivastava et al., 2020; Sur et al., 2021).

Lots of research has been done on the assessment of effect of lockdown on air quality in India based on ground data and satellite data (Dhaka et al., 2020; Kant et al., 2020; Lal et al., 2020; Mahato et al., 2020; Navinya et al., 2020; Pathakoti et al., 2020; Ranjan et al., 2020; Sharma et al., 2020; Siddiqui et al., 2020; Singh \& Nanda et al., 2021c; Srivastava et al., 2020). In Lucknow and New Delhi major impacts of lockdown were observed on the concentration of $\mathrm{PM}_{2.5}, \mathrm{NO}_{2}$, and $\mathrm{CO}$ and less on the $\mathrm{SO}_{2}$ (Srivastava et al., 2020). In Delhi and Mumbai $\mathrm{NO}_{2}$ concentration get declined by $40-50 \%$ due to Lockdown (Shehzad et al., 2020). When the data of air pollutant of the year 2018, 2019 and 2020 were compared for various cities of India, researchers found decrease in the concentration of $\mathrm{PM}_{2.5}, \mathrm{PM}_{10}$, and $\mathrm{O}_{3}$ as compared to the first two years but there were no change in the temperature and humidity (Bhawre, 2020; Navinya et al., 2020). Sur et al., (2021) reported $20-40 \%$ reduction in the concentration of $\mathrm{NO}_{2}$ over Indo-Gangetic region constitute the part of the current study. Kant et al., (2020) and Singh and Nanda (2020) reported reduction (35-46\%) in AOD over Northern India and Haryana state, respectively. Singh and Nanda et al. 2021c reported reduction in air pollutants over Haryana amid COVID-19 lockdown which resulted in the improvement of air quality index (44\%) and excess health risk $(71 \%)$ over the study area.

Efforts have also been put to understand the influences of meteorology on the concentration of air pollutants in the atmosphere (Banarjee et al., 2011; He et al., 2017; Ilten \& Selici, 2008; Jayamurugan et al., 2013; Navinya et al., 2020). Researchers found the influence of temperature on the concentration of $\mathrm{SO}_{2}$ and $\mathrm{NO}_{2}$. High influence is found in summer and rainy season, and low in other seasons in case of northern India. Relative humidity had no significant relation with $\mathrm{SO}_{2}$ and $\mathrm{NO}_{2}$ and negatively correlated with PM (Jayamurugan et al., 2013). Concentration of pollutants were positively correlated with temperature and negatively with wind speed and relative humidity (He et al., 2017). Pollutant concentration is low when the temperature or wind speed is high due to high rate of dispersion (Banerjee et al., 2011). However, little influence of meteorology was observed on air quality during lockdown period (Navinya et al., 2020).

Very few studies have focused a complete scenario starting from individual pollutant level to AQI to further health risk or Excess Risk (ER \%) due to COVID-19 driven lockdown (Sharma et al., 2020; Singh \& Nanda et al., 2021c). Further spatial studies related to ER \% over the currently taken region (part of Indo-Gangetic plain) is lacking except Singh and Nanda et al. 2021c in spite its urgent need. Sharma et al. (2020) reported 4 times reduction in total ER \% due to COVID-19 lockdown over various parts of India however, the spatial distribution of AQI, and ER\% were not attempted. Again the assessment during the lockdown in May 2021 is not reported yet in any of the earlier studies.

Thus, the current study is being done to analyse the variability in air pollutants, AQI and ER\% during January 2020 to June 2021 and in three scenarios viz. pre-lockdown (1 January 2020 to 21 March 2020), during lockdown (22 March 2020 to 31 May 2020) and post-lockdown (1 June 2020 to 30 June 2020) using ground based data, statistics, and GIS technologies. Efforts are also been put to understand the effect of meteorology on the concentration of pollutants especially due to the lockdown. The key objectives of the study are to (a) understand the variations of the pollutants concentration from January 2020 to June 2021 over the study area (b) Assess the impact of COVID-19 driven lockdown on air pollutants (c) Assess the variations in AQI and ER\% in response to COVID-19 driven lockdown. 


\section{Study Area}

Study area lies in Northern part of the India between Latitude $29^{\circ} 43^{\prime} 42.091$ and $32^{\circ} 34^{\prime} 27.131^{\prime \prime} \mathrm{N}$ and Longitude $75^{\circ} 51^{\prime} 45.409-78^{\circ} 29^{\prime} 26.983^{\prime \prime} \mathrm{N}$ and constitute part of Indo-Gangetic Plain (IGP) which is among the highly polluted regions in the world (Singh \& Dahiya et al., 2021a). It includes Districts of Haryana, Punjab, Rajasthan, Uttar Pradesh (PU), Delhi and Union territory of Chandigarh (Fig. 1). The study area was selected based on the continuous data availability from ground-based stations. It was also considered that the stations are well distributed over the study area. A total of 47 ground stations for air pollutants measurement were taken in the study area, working under the maintenance of central pollution control board (CPCB). The total geographical area is 191032 ha and largely covered by agriculture and built-up/habitation. The elevation ranges from 140 to $673 \mathrm{~m}$. The annual average rainfall is $\sim 740 \mathrm{~mm}$ with arid to semi-arid type of climate.

It is affected by both type of air pollution sources, i.e. natural (dusty wind from Thar desert of arid Rajasthan) and anthropogenic (like biomass and crop stubble burning, Industrial activities, dense population and high transport/ vehicular movements) depending on the season and time (Huang et al., 2018). Further the topography and weather conditions also influences the pollution level of the study area especially during monsoon (June-September) and winter (November-February). Taking the geographical location, population density, ground data availability, and persistent air pollution problem throughout the year (increased pollution in May and October-December every year as reported by Singh and Kundu et al. (2021b) and c among others) into the consideration, the current study area need to be examined exhaustively for a better air quality management.

The current COVID-19 condition has largely affected the anthropogenic activities in the region and thus the changes in the level of air pollutants, AQI, and ER\% is considered to be influenced by this (Navinya et al., 2020; Sharma et al., 2020). The consistencies in natural pollution favouring conditions have also been reported by Bhawre (2020) for these regions. Study area includes 196 blocks distributed in 37 districts of six states and Union Territory
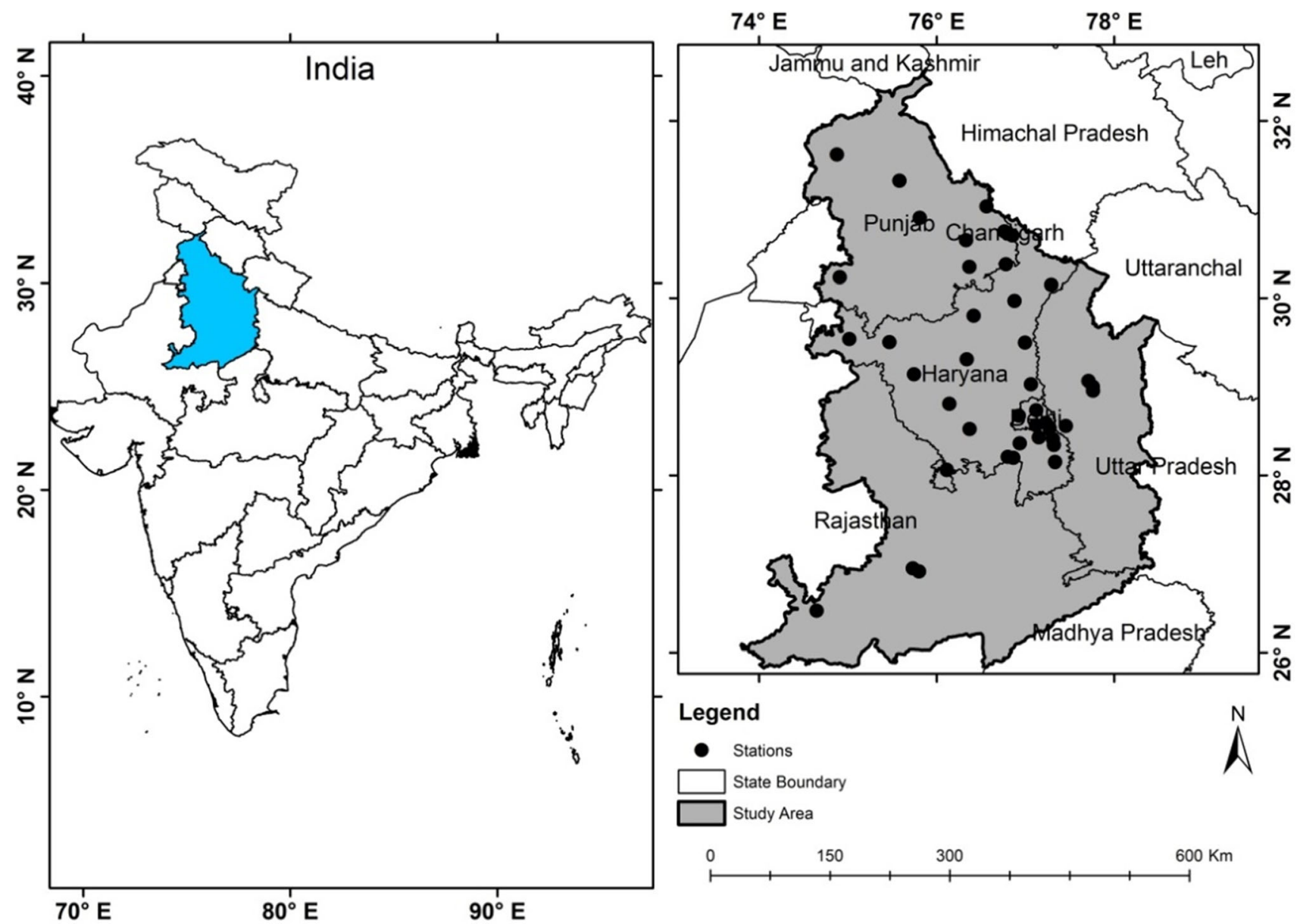

Fig. 1 Study Area Map 
having 47 ground stations. A map showing these administrative units is given in Fig. S1 (in supplementary material) and list of the administrative units (name of the 196 blocks) are given in Table A1 (supplementary material).

\section{Methodology}

Daily and monthly variation of the air pollutants over the whole study area was presented in the form of time series graph and as mean \pm standard deviation (SD), respectively. Influence of COVID-19 driven lockdown on air pollution, AQI, and related ER \% was assessed taking three scenarios into account viz. pre-lockdown, during lockdown, and post-lockdown. Pollutant concentrations from ground stations were processed for AQI and ER \% in GIS environment through Invers Distance Weighted (IWD) interpolation for assessing spatial variability in pre-defined scenarios. Flowchart of methodology is presented in Fig. 2.

\section{Data Source}

To assess the AQI and related ER\% of selected study area on a monthly basis and in predefined scenarios namely prelockdown, during lockdown and post-lockdown, the ground data from CPCB stations $(n=47)$ were downloaded for a period of 1.5 years starting from 01 January 2020 to 30 June 2021 on daily temporal resolution from https://app.cpcbccr.com/ccr/\#/caaqm-dashboard-all/caaqmlanding/caaqm-comparison-data. Since the meteorological data for 2021 were limited data for 2019 (January to June) were also downloaded and used in the correlation analysis between pollutants and meteorological parameters. The correlation analysis was done to understand the influence of meteorology on the pollutants concentration with assumption that the correlation would be high for influential meteorological parameters.

Ground stations are distributed at the various parts of the different states and territory in northern India (Delhi, Chandigarh, Haryana, Punjab, Uttar Pradesh, and Rajasthan). Daily concentration of seven criteria pollutants $\left(\mathrm{PM}_{2.5}, \mathrm{PM}_{10}, \mathrm{NO}_{2}, \mathrm{NH}_{3}, \mathrm{CO}, \mathrm{O}_{3}\right.$, and $\mathrm{SO}_{2}$. $)$ has been processed at individual station level. The CPCB facility provides 24-h average concentration of the $\mathrm{PM}_{2.5}, \mathrm{PM}_{10}$, $\mathrm{NO}_{2}, \mathrm{NH}_{3}, \mathrm{SO}_{2}$, and 8-h average $\mathrm{CO}, \mathrm{O}_{3}$, respectively. Stations along with their geographical coordinates are listed in Table 1.

\section{Statistics of Criteria Pollutants}

The criteria pollutants were assessed including $\mathrm{PM}_{2.5}$, $\mathrm{PM}_{10}, \mathrm{NO}_{2}, \mathrm{NH}_{3}, \mathrm{CO}, \mathrm{O}_{3}$, and $\mathrm{SO}_{2}$ on a daily basis from January 2020 to June 2021. Statistical analysis was done for the description of the concentration of all pollutants (for whole time period on a monthly basis as well as for three scenarios) which includes the mean, and SD. Mobility related data from apple navigation facility were also used to link pollutants variation amid COVID-19 (Fig. 3). Variation in pollutant concentration over Delhi (Fig. 4a-d), Haryana (Fig. 4e-h), and Punjab (Fig. 4i-l) during January 2020 to June 2021 and related controls are presented in Fig. 4a-1. These data were further analysed for the effect of COVID-19 driven lockdown on air pollutants.
Fig. 2 Flowchart of method applied for the current study

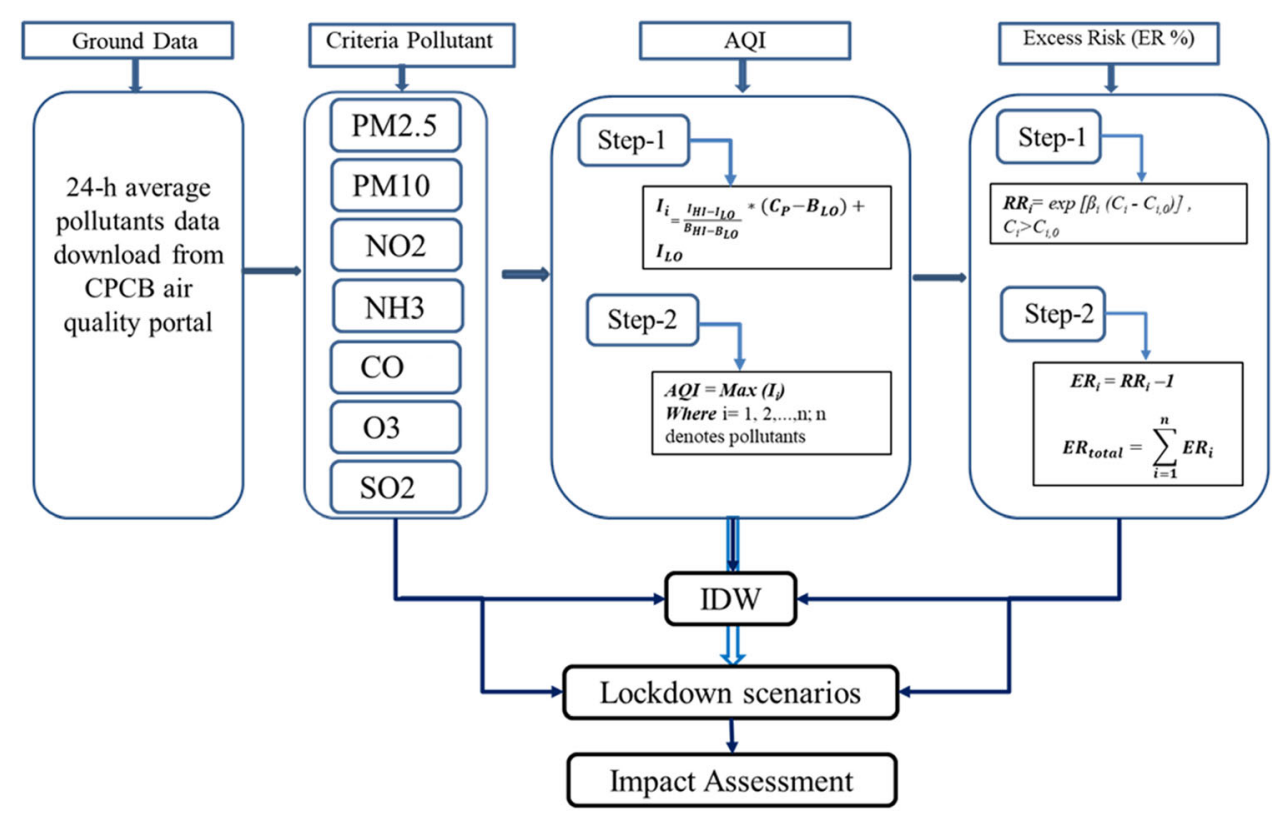


Table 1 Ground monitoring stations of study area. Source Central Control Room for Air Quality Management

\begin{tabular}{|c|c|c|c|}
\hline Sl.no & Station name & Latitude & Longitude \\
\hline 1 & Patti Mehar, Ambala & 76.77833 & 30.37959 \\
\hline 2 & Arya Nagar, Bahadurgarh,jhajjar & 76.92540 & 28.67010 \\
\hline 3 & Nathu Colony, Ballabgarh,Faridabad & 77.31970 & 28.34192 \\
\hline 4 & H.B. Colony, Bhiwani & 76.14111 & 28.80622 \\
\hline 5 & Municipal Corporation Office, Dharuhera,Rewari & 76.79970 & 28.20680 \\
\hline 6 & Sector- 16A, Faridabad & 77.30991 & 28.40884 \\
\hline 7 & Huda Sector, Fatehabad & 75.46793 & 29.50366 \\
\hline 8 & NISE Gwal Pahari, Gurugram-IMD & 77.15000 & 28.42600 \\
\hline 9 & Urban Estate-II, Hisar & 75.74494 & 29.14056 \\
\hline 10 & Police Lines, Jind & 76.33762 & 29.30781 \\
\hline 11 & Rishi Nagar, Kaithal & 76.41550 & 29.80060 \\
\hline 12 & Sector-12, Karnal & 77.00270 & 29.69530 \\
\hline 13 & Sector-7, Kurukshetra & 76.87588 & 29.96694 \\
\hline 14 & General Hospital, Mandikhera,Mewat & 76.99380 & 27.90020 \\
\hline 15 & Sector-2 IMT, Manesar, Gurugram & 76.93609 & 28.36070 \\
\hline 16 & Shastri Nagar, Narnaul,Mahendergarh & 76.11312 & 28.06025 \\
\hline 17 & Shyam Nagar, Palwal & 77.33207 & 28.14856 \\
\hline 18 & Sector-6, Panchkula & 76.85318 & 30.70578 \\
\hline 19 & Sector-18, Panipat & 76.99333 & 29.49797 \\
\hline 20 & MD University, Rohtak & 76.37138 & 28.52123 \\
\hline 21 & F-Block, Sirsa & 75.01580 & 29.53640 \\
\hline 22 & Murthal, Sonipat & 77.06210 & 29.02720 \\
\hline 23 & Gobind Pura, Yamuna Nagar & 77.28935 & 30.14806 \\
\hline 24 & RIICO Ind. Area III, Bhiwadi,Alwar & 76.86230 & 28.19491 \\
\hline 25 & Hardev Nagar, Bathinda & 74.90776 & 30.23301 \\
\hline 26 & Model Town, Patiala & 76.36664 & 30.34939 \\
\hline 27 & RIMT University, Mandi Gobindgarh, Fatehgarh & 76.33144 & 30.64996 \\
\hline 28 & Kalal Majra, Khanna,Ludhiana & 76.20969 & 30.73606 \\
\hline 29 & Sector-25, Chandigarh & 76.76288 & 30.75146 \\
\hline 30 & Punjab Agricultural University, Ludhiana & 75.80860 & 30.90280 \\
\hline 31 & Civil Line, Jalandhar & 75.57891 & 31.32191 \\
\hline 32 & Ratanpura, Rupnagar & 76.56230 & 31.03255 \\
\hline 33 & Golden Temple, Amritsar & 74.87651 & 31.62000 \\
\hline 34 & New Mandi, Muzaffarnagar & 77.71940 & 29.47235 \\
\hline 35 & Pallavpuram Phase 2, Meerut & 77.70972 & 29.06351 \\
\hline 36 & Ganga Nagar, Meerut & 77.75904 & 28.99926 \\
\hline 37 & Jai Bhim Nagar, Meerut & 77.76229 & 28.95359 \\
\hline 38 & Knowledge Park—V, Greater Noida, & 77.45366 & 28.55705 \\
\hline 39 & Rohini, Delhi & 77.11992 & 28.73253 \\
\hline 40 & Lodhi Road, Delhi & 77.22731 & 28.59182 \\
\hline 41 & Sri Aurobindo Marg & 77.19016 & 28.53135 \\
\hline 42 & Okhla Phase-2, Delhi & 77.27126 & 28.53079 \\
\hline 43 & IGI Airport (T3), Delhi & 77.11801 & 28.56278 \\
\hline 44 & Shastri Nagar, Jaipur & 75.73094 & 26.95029 \\
\hline 45 & Police Commissionerate, Jaipur & 75.79949 & 26.91641 \\
\hline 46 & Adarsh Nagar, Jaipur & 75.83685 & 26.90291 \\
\hline 47 & Civil Lines, Ajmer & 74.64659 & 26.47086 \\
\hline
\end{tabular}




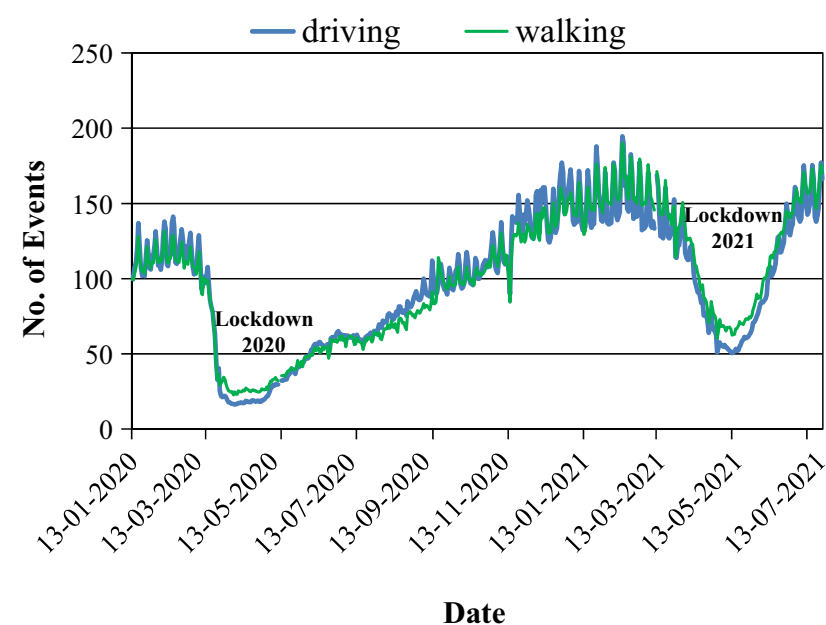

Fig. 3 Driving and walking trend in India during last 1.5 years (Jan 2020 to July 2021) of the study period ( source: https://covid19.apple. com/mobility)

\section{Air Quality Index (AQI)}

AQI defines the transformation of the weighted value of the parameters of air pollutants into the single, unit less number (Singh \& Nanda et al., 2021c). Out of all the criteria pollutants viz. $\mathrm{PM}_{2.5}, \mathrm{PM}_{10}, \mathrm{NO}_{2}, \mathrm{NH}_{3}, \mathrm{CO}, \mathrm{O}_{3}$, and $\mathrm{SO}_{2}$ a minimum of three pollutants should be available and one should be $\mathrm{PM}_{10}$ or $\mathrm{PM}_{2.5}$ as suggested by CPCB. AQI scale varies from 0 to 500 and divided into six categories viz. Good (0-50), Satisfactory (51-100), Moderate (101200), Poor (201-300), Very poor (301-400) and Severe (401-500). Two steps are involved into the AQI calculation. In first step, Sub-Index is calculated for each air pollutant by using the following formula (Kanchan et al., 2016; Singh \& Nanda et al., 2021c).

$\mathrm{I}_{\mathrm{i}}=\frac{\mathrm{I}_{\mathrm{HI}}-\mathrm{I}_{\mathrm{LO}}}{\mathrm{B}_{\mathrm{HI}}-\mathrm{B}_{\mathrm{LO}}} *\left(\mathrm{C}_{\mathrm{P}}-\mathrm{B}_{\mathrm{LO}}\right)+\mathrm{I}_{\mathrm{LO}}$

where $I_{i}=$ Sub index $I_{H I}=A Q I$ value corresponding of the $\mathrm{B}_{\mathrm{HI}} \mathrm{B}_{\mathrm{HI}}=$ Greater breakdown concentration $\mathrm{I}_{\mathrm{LO}}=\mathrm{AQI}$ value corresponding of the $\mathrm{B}_{\mathrm{LO}} \mathrm{B}_{\mathrm{LO}}=$ Smaller breakdown concentration $\mathrm{C}_{\mathrm{p}}=$ Concentration of pollutant.

In the second step, $\mathrm{AQI}$ is calculated from the maximum concentration of the sub-index of the all air pollutant, as shown in equation two.

$\mathrm{AQI}=\operatorname{Max}\left(I_{i}\right)$

where $\mathrm{i}=1,2, \ldots, \mathrm{n} ; \mathrm{n}$ denotes pollutants.

Concentration ranges for individual pollutants those limits the categories of AQI are listed in Table 2. These limits are called break points and identified by CPCB for AQI estimation. Further, the average values of AQI in three scenarios were analysed both statistically as well as in spatial domain for understanding the effect of COVID-19 driven lockdown. Inverse distance weighting (IDW) method of spatial interpolation is used for understanding variations of air pollutants in spatial domain following Kumar et al. (2016) and Singh and Nanda et al. 2021c. IDW works on the assumption that the things those are close to one another are similar than those are farther apart. It estimates the values of unknown locations from the average values of the available neighbour locations taking inverse of their distances into consideration. IDW is a deterministic spatial interpolation approach to estimate a missing value from given values as presented in Eq. 3 (http://www.gitta.info/ContiSpatVar/en/html/Interpolatio_ learning Object2.xhtml).

$v=\frac{\sum_{i=1}^{n} \frac{v_{i}}{d_{i}}}{\sum_{i=1}^{n} \frac{1}{d_{i}}}$

where $v=$ value to be estimated. $v_{\mathrm{i}}=$ known value. $d_{\mathrm{i}} \ldots \ldots . d_{\mathrm{n}}=$ distances from the $\mathrm{n}$ data points to the point estimated $n$.

This technique has been found to be applicable for the interpolation of air pollutants (Kumar et al., 2016; Singh and Nanda et al., 2021c); however, there are some drawbacks like (a) It is not able to estimate above of the maximum and less than the minimum value (b) not good for peaks and mountains area. Since our study area is flat terrain this method may provide acceptable results. Maps of the concentration of the air pollutants are also prepared and presented in Fig. 5a-d and in Figs. S2-S4 (supplementary materials).

\section{Health Risk Calculations}

Health risk from the air pollutant is measured in term of exposure of the human being from the concentration of the each pollutant (Sharma et al., 2020). Pollutants concentration is changed with time and location so health risk of the area is also variable. For the health risk assessment, ER\% was considered. The ER\% was estimated based on Relative Risk (RR) of each pollutant. RR of the each pollutant are estimated by following Eq. 4 (Sharma et al., 2020; Singh \& Nanda et al., 2021c).

$\mathrm{RR}_{i}=\exp \left[\beta_{i}\left(\mathrm{C}_{i}-\mathrm{C}_{i, 0}\right)\right], \mathrm{C}_{i}>\mathrm{C}_{i, 0}$

where $\mathrm{RR}_{i}$ is the Relative risk of pollutant $i, \beta_{\mathrm{i}}$ is exposure response coefficient of additional health risk (Such as mortality) caused by per unit of pollutant $i$, when it exceeds a thresholds concentration. $C_{i}$ is the concentration of the pollutant $i$ and $C_{i, 0}$ is the threshold concentration of pollutant (when threshold concentration of pollutant is less than the pollutant concentration then relative risk is greater than 0 ). $\beta_{\mathrm{i}}$ and threshold value taken for the present study are presented in Table 3. ER $i \%$ and total ER\% of the 

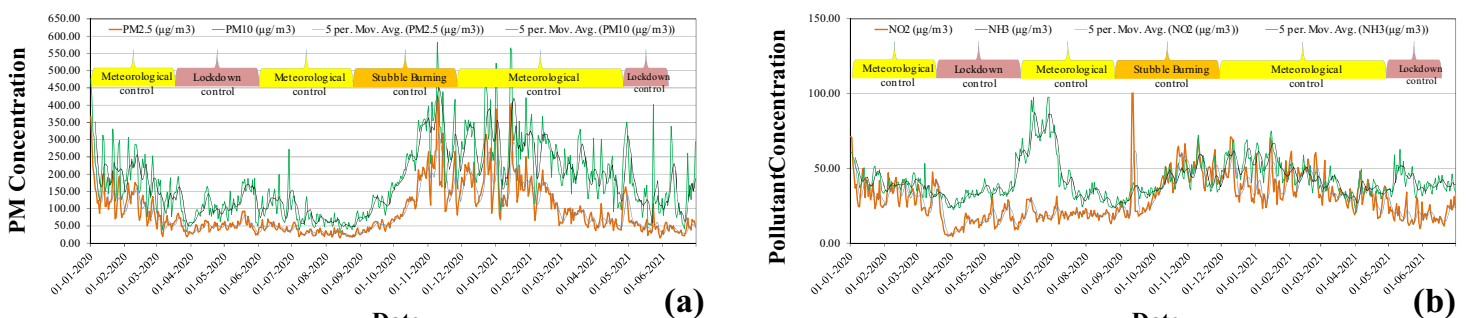

Date

(a)

Date

(b)
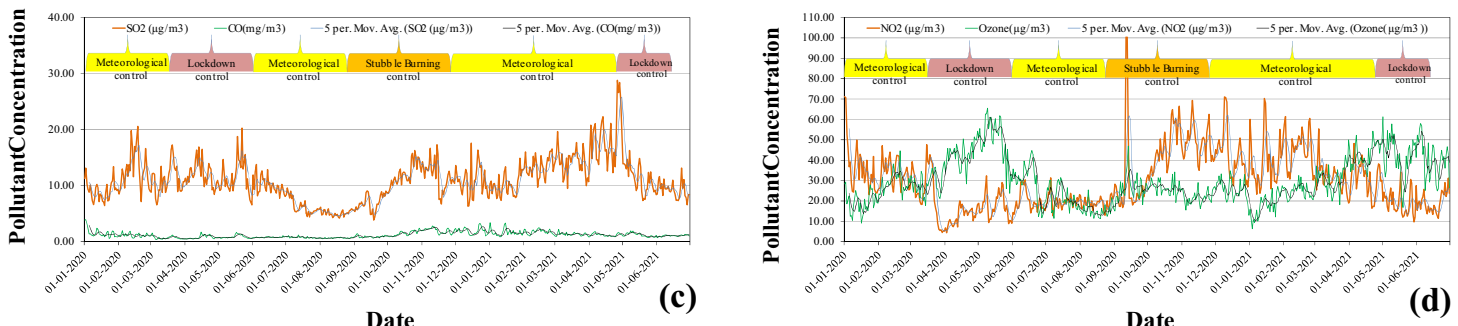

Date

Date

(d)

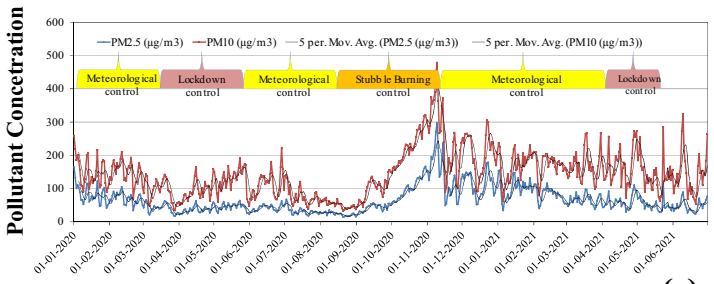

Date

(e)

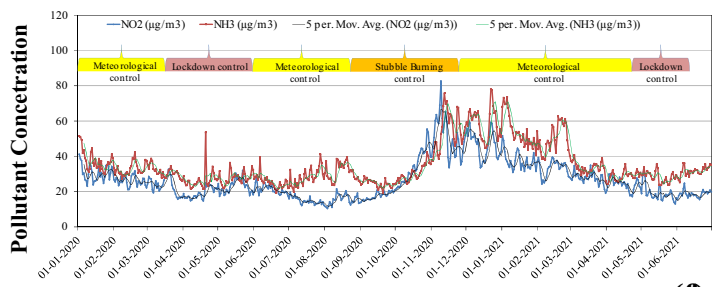

Date

(f)
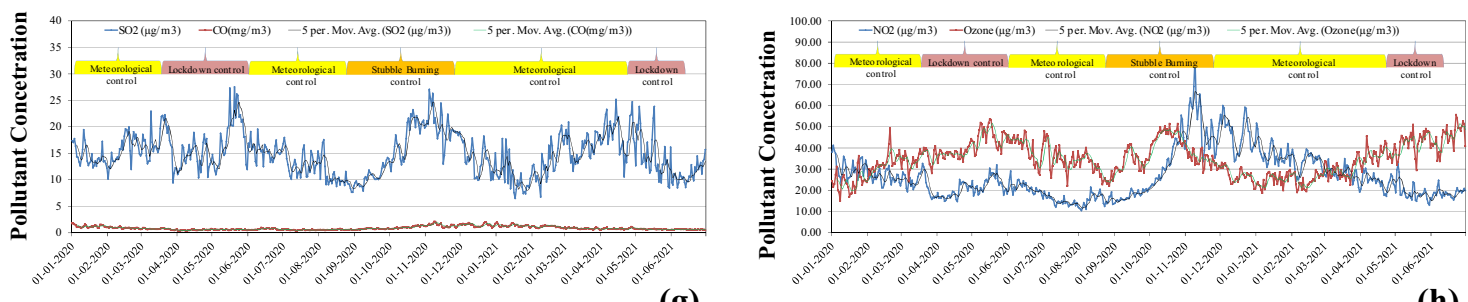

Date

(g)

Date

(h)
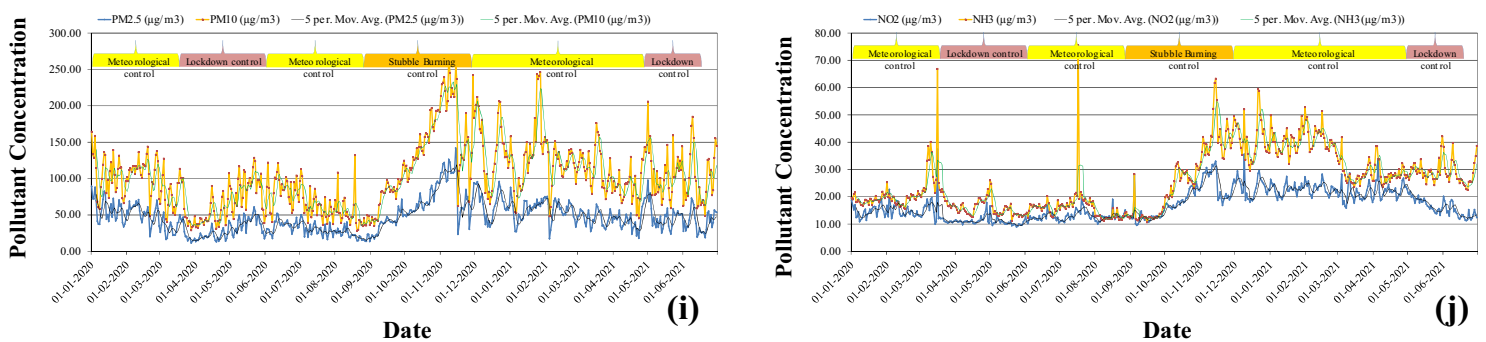

Date

(j)
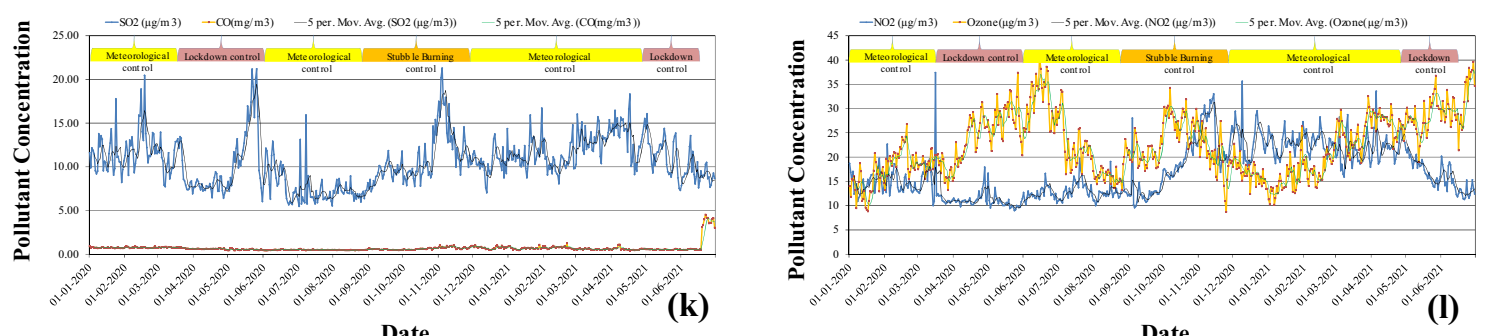

Fig. 4 Variation in pollutant concentration over Delhi (a-d), Haryana (e-h), and Punjab (i-l) during last 1.5 years (Jan 2020 to June 2021$)$ and related controls 
Table 2 Breakdown for AQI scale of all Air Pollutant. Source (CPCB, 2014)

\begin{tabular}{lllllllll}
\hline AQI category & \multicolumn{2}{l}{ Concentration range } \\
\cline { 2 - 8 } & $\mathrm{PM}_{2.5}$ & $\mathrm{PM}_{10}$ & $\mathrm{NO}_{2}$ & $\mathrm{NH}_{3}$ & $\mathrm{CO}$ & $\mathrm{O}_{3}$ & $\mathrm{SO}_{2}$ & $\mathrm{~Pb}$ \\
\hline Good & $0-30$ & $0-50$ & $0-40$ & $0-200$ & $0-1.0$ & $0-50$ & $0-40$ & $0-0.5$ \\
Satisfactory & $31-60$ & $51-100$ & $41-80$ & $201-400$ & $1.1-2.0$ & $51-100$ & $41-80$ & $0.5-1.0$ \\
Moderate & $61-90$ & $101-250$ & $81-180$ & $401-800$ & $2.1-10$ & $101-168$ & $81-380$ & $1.1-1.2$ \\
Poor & $91-120$ & $251-350$ & $181-280$ & $801-1200$ & $10-17$ & $169-208$ & $381-800$ & $2.1-3.0$ \\
Very poor & $121-250$ & $351-430$ & $281-400$ & $1200-1800$ & $17-34$ & $209-748$ & $801-1600$ & $3.1-3.5$ \\
Severe & $250+$ & $430+$ & $400+$ & $1800+$ & $34+$ & $748+$ & $1600+$ & $3.5+$ \\
\hline
\end{tabular}

$\mathrm{CO}$ and $\mathrm{O}_{3}$ are 8-h average concentration and other pollutants are 24-h average concentration and $\mathrm{CO}$ is measured in $\mathrm{mg} / \mathrm{m}_{3}$ and other pollutant measured in $\mu \mathrm{g} / \mathrm{m}^{3}$ pollutant is estimated by using Eqs. 5, 6 (Sharma et al., 2020; Singh \& Nanda et al., 2021c).

$$
\begin{aligned}
& \mathrm{ER}_{i}=\mathrm{RR}_{i}-1 \\
& \mathrm{ER}_{\text {total }}=\sum_{i=1}^{n} \mathrm{ER}_{i}
\end{aligned}
$$

\section{Results}

\section{Variations in Criteria Pollutants Over the Study Area}

Pattern and statistical analysis was done by using the ground data from January 2020 to June 2021. Daily and monthly variations in the concentration of all pollutants are shown in Fig. 4a-1 and in Table 4, respectively. Daily variation in the pollutant concentration over Delhi (Fig. 4a-d), Haryana (Fig. 4e-h) and Punjab (Fig. 4i-l) show specific pattern with high values during winter (December-February) and low values during summer (March-April) and rainy season (June-September). The peaks were observed during the Month of October and November (Fig. 4a-1) which is attributed to the stubble burning in both 2020 and 2021; however, the influence of Lockdown could be seen during April 2020 and May 2021 (Table 4). The reduction in pollutant level amid lockdown was less in 2021 as compared to 2020 (Table 4).

\subsection{Impact of COVID-19 Driven Lockdown on the Concentration of Criteria Pollutants}

Descriptive statistical analysis was done for three scenarios and results are presented in Table 5. Mean and SD of criteria pollutants viz. $\mathrm{PM}_{2.5}, \mathrm{PM}_{10}, \mathrm{NO}_{2}, \mathrm{NH}_{3}, \mathrm{CO}, \mathrm{O}_{3}$, and $\mathrm{SO}_{2}$ were $71 \pm 45 \mu \mathrm{g} / \mathrm{m}^{3}, 139 \pm 72 \mu \mathrm{g} / \mathrm{m}^{3}, 28 \pm 21 \mu \mathrm{g} /$ $\mathrm{m}^{3}, 33 \pm 24 \mu \mathrm{g} / \mathrm{m}^{3}, 1.00 \pm 0.65 \mathrm{mg} / \mathrm{m}^{3}, 29 \pm 20 \mu \mathrm{g} / \mathrm{m}^{3}$ and $13.8 \pm 11 \mu \mathrm{g} / \mathrm{m}^{3}$ in pre-lockdown, $39 \pm 20 \mu \mathrm{g} / \mathrm{m}^{3}$, $96 \pm 55 \mu \mathrm{g} / \mathrm{m}^{3}, \quad 17 \pm 13 \mu \mathrm{g} / \mathrm{m}^{3}, \quad 25 \pm 18 \mu \mathrm{g} / \mathrm{m}^{3}$,
$0.7 \pm 0.5 \mathrm{mg} / \mathrm{m}^{3}, 39 \pm 23 \mu \mathrm{g} / \mathrm{m}^{3}$ and $13.7 \pm 11.6 \mu \mathrm{g} / \mathrm{m}^{3}$ were during lockdown and $40 \pm 17 \mu \mathrm{g} / \mathrm{m}^{3}, 105 \pm 57 \mu \mathrm{g} /$ $\mathrm{m}^{3}, \quad 18 \pm 12 \mu \mathrm{g} / \mathrm{m}^{3}, \quad 29 \pm 22 \mu \mathrm{g} / \mathrm{m}^{3}, \quad 0.7 \pm 0.6 \mathrm{mg} / \mathrm{m}^{3}$, $39 \pm 22 \mu \mathrm{g} / \mathrm{m}^{3}$ and $12.7 \pm 8.9 \mu \mathrm{g} / \mathrm{m}^{3}$ were in post-lockdown. The concentration of $\mathrm{PM}_{2.5}, \mathrm{PM}_{10}, \mathrm{NO}_{2}, \mathrm{NH}_{3}$, and CO decreased by $46 \%, 31 \%, 39 \%, 24 \%$ and $34 \%$ in lockdown scenario as compared to the pre-lockdown scenario. The concentration of $\mathrm{PM}_{10}, \mathrm{PM}_{2.5}, \mathrm{NO}_{2}, \mathrm{NH}_{3}$, and $\mathrm{CO}$ shows clear cut reduction due to lockdown as movements of both the vehicle and human was restricted during the lockdown condition (Fig. 3) and most of the anthropogenic activities were delimited.

$\mathrm{SO}_{2}$ concentration was similar in pre-lockdown and during lockdown may be due to no restriction on the power plant operations during lockdown period. $\mathrm{O}_{3}$ concentration was increased during lockdown may be due to presence of clear sky condition, sun light and ozone forming nuclei's, i.e. $\mathrm{NO}_{\mathrm{x}}$ and $\mathrm{VOC}_{\mathrm{s}}$. Inter-correlation between pollutants showed that the $\mathrm{PM}_{2.5}$ and $\mathrm{PM}_{10}$ are highly correlated with each other $\left(r^{2}=>0.6\right)$ and in agreement with earlier study done by Wai et al. (2013). However, other pollutants were found to be less correlated. Individual pollutant concentrations showed high values during pre-lockdown, lowest values during lockdown and medium values during post-lockdown (Fig. 5a-d); however, the differences were less during and post-lockdown. The minor differences in the values may be due to lockdown in April and Meteorology during June (Table 4). Nevertheless, the concentration of pollutants remained high during January and February which get decreased during March and April. Reduction in pollutant level after lockdown on 24 march 2020 may also be seen in Fig. 4(a-l) except for $\mathrm{O}_{3}$ following the earlier findings of Siddiqui et al. (2020), Sur et al. (2021), and Singh and Nanda et al. 2021c among others. In the last week of April and during May, the process of stubble burning get started which have compensated the reduced level of pollutants due to lockdown amid COVID-19 (Fig. S5 supplementary material). The decreasing pattern of the pollutants (especially $\mathrm{PM}_{2.5}$ and 


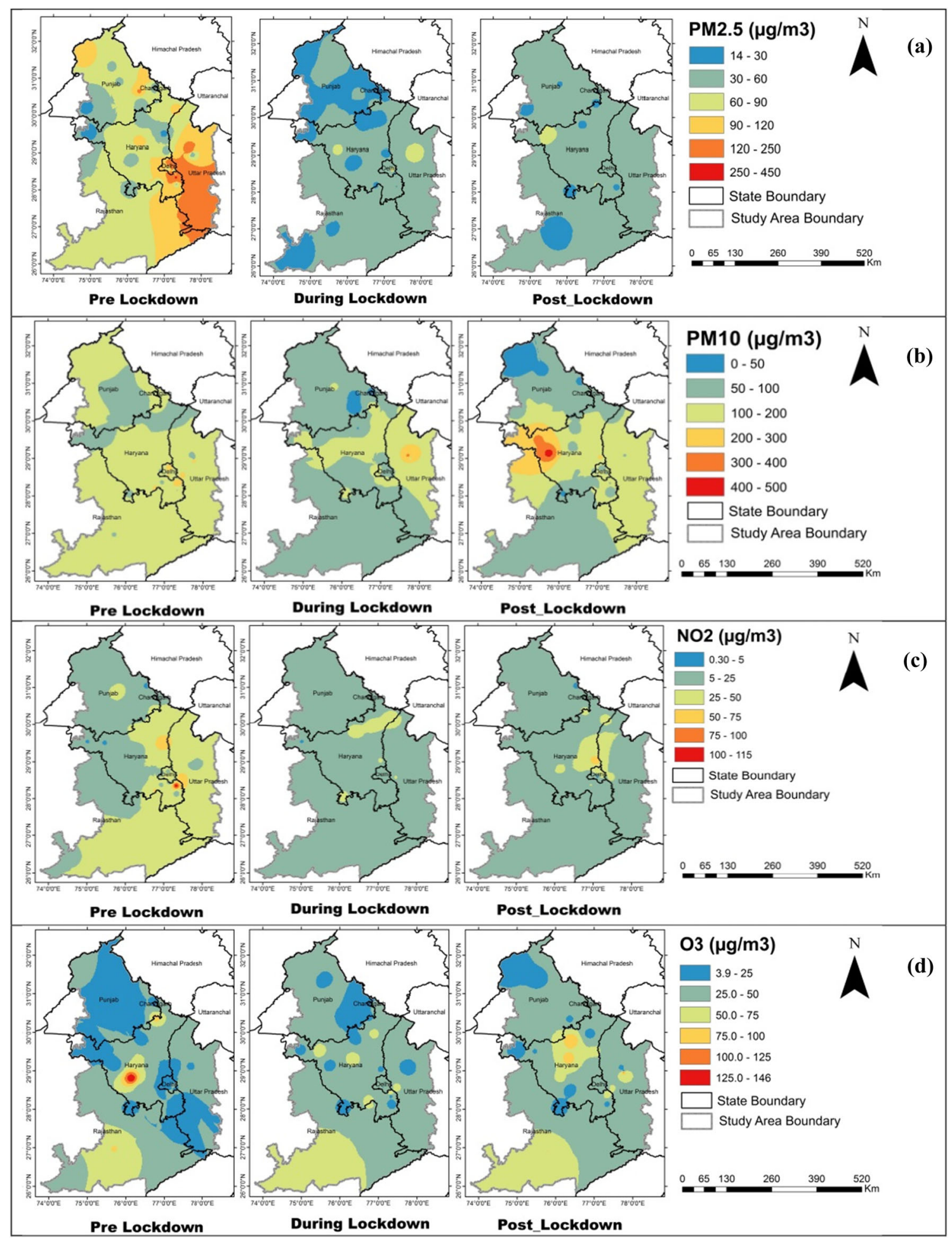

Fig. 5 Variations in Pollutant concentration in three scenarios viz. Pre, During and Post-Lockdown over the study area

$\mathrm{PM}_{10}$ ) is also observed during June due to meteorological conditions (Fig. 4a-1). It was observed that the pollutants concentration was high during lockdown (May 2020) as compared to the post-lockdown (June 2020) probably due to (a) compensation of reduced air pollutants from stubble burning emission and (b) less pollutants concentration during June supported by meteorological conditions (Table 4). Further, there was less reduction in pollutant concentration during the lockdown in 2021 (Table 4). 
Table $3 \beta_{i}$ and threshold value for each criteria pollutant required for Relative Risk (RR) estimation

\begin{tabular}{llllll}
\hline S.no & $\begin{array}{l}\mathrm{PM}_{2.5} \mu \mathrm{g} / \mathrm{m}^{3} \\
(24-\mathrm{h})\end{array}$ & $\begin{array}{l}\mathrm{PM}_{10} \mu \mathrm{g} / \mathrm{m}^{3} \\
(24-\mathrm{h})\end{array}$ & $\begin{array}{l}\mathrm{NO}_{2} \mu \mathrm{g} / \mathrm{m}^{3} \\
(24-\mathrm{h})\end{array}$ & $\begin{array}{l}\mathrm{CO} \mathrm{mg} / \mathrm{m}^{3} \\
(24-\mathrm{h})\end{array}$ & $\begin{array}{l}\mathrm{SO}_{2} \mu \mathrm{g} / \mathrm{m}^{3} \\
(24-\mathrm{h})\end{array}$ \\
\hline$\beta$-Value & $0.038 \%$ & $0.032 \%$ & $0.13 \%$ & $3.7 \%$ & $0.081 \%$ \\
Threshold value & 35 & 50 & 40 & 2 & 50 \\
\hline
\end{tabular}

Table 4 Statistics for concentration of Air Pollutants (in $\mu \mathrm{g} / \mathrm{m}^{3}$ for all parameters except CO which in $\mathrm{mg} / \mathrm{m}^{3}$ ) during Jan 2020 to June 2021

\begin{tabular}{|c|c|c|c|c|c|c|c|c|c|}
\hline & $\begin{array}{l}\mathrm{PM}_{2.5} \\
\text { Mean } \pm \mathrm{SD}\end{array}$ & $\begin{array}{l}\mathrm{PM}_{10} \\
\text { Mean } \pm \mathrm{SD}\end{array}$ & $\begin{array}{l}\mathrm{NO}_{2} \\
\text { Mean } \pm \mathrm{SD}\end{array}$ & $\begin{array}{l}\mathrm{NH}_{3} \\
\text { Mean } \pm \mathrm{SD}\end{array}$ & $\begin{array}{l}\mathrm{SO}_{2} \\
\text { Mean } \pm \mathrm{SD}\end{array}$ & $\begin{array}{l}\mathrm{CO} \\
\text { Mean } \pm \mathrm{SD}\end{array}$ & $\begin{array}{l}\mathrm{O}_{3} \\
\text { Mean } \pm \mathrm{SD}\end{array}$ & $\begin{array}{l}\text { AQI } \\
\text { Mean } \pm \text { SD }\end{array}$ & $\begin{array}{l}\text { ER\% } \\
\text { Mean }\end{array}$ \\
\hline \multicolumn{10}{|l|}{2020} \\
\hline Jan & $85 \pm 55.7$ & $149.61 \pm 84$ & $30.3 \pm 22.6$ & $35.9 \pm 25$ & $12.7 \pm 11.12$ & $1.1 \pm 0.8$ & $23 \pm 16.3$ & $183 \pm 62$ & 3.36 \\
\hline Feb & $72.5 \pm 35.4$ & $148 \pm 65$ & $28 \pm 20$ & $32 \pm 22$ & $14 \pm 10$ & $1 \pm 0.5$ & $31 \pm 20$ & $171 \pm 65$ & 3.10 \\
\hline March & $40.8 \pm 22$ & $92.8 \pm 51.5$ & $21.8 \pm 17.4$ & $29.6 \pm 23$ & $14 \pm 11$ & $0.8 \pm 0.5$ & $33 \pm 22$ & $105 \pm 52$ & 1.89 \\
\hline April & $34.8 \pm 17.8$ & $85 \pm 48.5$ & $16 \pm 12.5$ & $24.3 \pm 18.2$ & $12.3 \pm 8.7$ & $0.64 \pm 0.50$ & $36.8 \pm 20.5$ & $96 \pm 49$ & 2.24 \\
\hline May & $44.7 \pm 20.6$ & $116.8 \pm 57$ & $19 \pm 14.7$ & $26.2 \pm 17.3$ & $15.1 \pm 14.1$ & $0.7 \pm 0.4$ & $43 \pm 24.5$ & $118 \pm 57$ & 2.48 \\
\hline June & $39.7 \pm 16.8$ & $102.7 \pm 56.6$ & $18.2 \pm 12$ & $29.1 \pm 22.3$ & $12.41 \pm 12.44$ & $0.7 \pm 0.5$ & $38.6 \pm 22$ & $112 \pm 57$ & 1.94 \\
\hline July & $31.7 \pm 18.7$ & $74 \pm 46.8$ & $16 \pm 10$ & $29 \pm 22$ & $10.7 \pm 12.3$ & $0.60 \pm 0.35$ & $31.3 \pm 21.1$ & $85 \pm 47$ & 1.32 \\
\hline August & $23.1 \pm 11.4$ & $52.1 \pm 34.4$ & $15.2 \pm 11.8$ & $26.4 \pm 23.2$ & $9.1 \pm 8$ & $0.60 \pm 0.45$ & $24.4 \pm 17.8$ & $64 \pm 34$ & 0.80 \\
\hline Sept & $41.5 \pm 20.5$ & $95.2 \pm 47$ & $18.8 \pm 20.2$ & $23.8 \pm 17.7$ & $10 \pm 8$ & $0.7 \pm 0.5$ & $29.8 \pm 17.1$ & $109 \pm 48$ & 1.82 \\
\hline Oct & $96 \pm 50.5$ & $207.5 \pm 90.4$ & $34.3 \pm 27.8$ & $33.7 \pm 24.3$ & $15.4 \pm 11.2$ & $1.0 \pm 0.6$ & $40.5 \pm 24.6$ & $224 \pm 91$ & 5.23 \\
\hline Nov & $137.8 \pm 94.5$ & $251 \pm 137.3$ & $47.3 \pm 36.7$ & $52 \pm 41$ & $18 \pm 15.2$ & $1.3 \pm 0.8$ & $32.5 \pm 23$ & $279 \pm 138$ & 6.58 \\
\hline Dec & $116 \pm 71$ & $212 \pm 108$ & $44.7 \pm 37$ & $54.6 \pm 41.3$ & $13 \pm 10$ & $1.3 \pm 0.8$ & $26.4 \pm 19$ & $240 \pm 110$ & 5.37 \\
\hline \multicolumn{10}{|l|}{2021} \\
\hline Jan & $105 \pm 69$ & $185 \pm 111$ & $42 \pm 41$ & $51 \pm 38$ & $11.16 \pm 11.22$ & $1.2 \pm 0.8$ & $23.5 \pm 21.2$ & $211 \pm 94$ & 5.82 \\
\hline Feb & $87.2 \pm 47.5$ & $181 \pm 90$ & $37.3 \pm 28$ & $48.4 \pm 44.5$ & $13.5 \pm 12$ & $1.14 \pm 0.6$ & $24.4 \pm 17.6$ & $194 \pm 90$ & 6.02 \\
\hline March & $66.1 \pm 32.7$ & $172.7 \pm 86.4$ & $33.6 \pm 38.4$ & $36.4 \pm 27.7$ & $17 \pm 12.5$ & $0.8 \pm 0.5$ & $31.7 \pm 22.7$ & $141 \pm 85$ & 2.67 \\
\hline April & $62.5 \pm 38$ & $164 \pm 87$ & $30.5 \pm 38$ & $32 \pm 26.4$ & $19.3 \pm 14.5$ & $0.8 \pm 0.5$ & $38 \pm 26.5$ & $155 \pm 87$ & 4.31 \\
\hline May & $50.3 \pm 27.7$ & $132.4 \pm 69.2$ & $19.34 \pm 19$ & $30 \pm 21.7$ & $14.25 \pm 14.4$ & $0.7 \pm 0.5$ & $40 \pm 27$ & $125 \pm 70$ & 3.58 \\
\hline June & $46.7 \pm 24.5$ & $132.3 \pm 82$ & $19 \pm 14$ & $31 \pm 23$ & $11.5 \pm 9$ & $0.96 \pm 2.8$ & $41.2 \pm 26$ & $129 \pm 77$ & 3.77 \\
\hline
\end{tabular}

\subsection{Impact of COVID-19 Driven Lockdown on Air Quality Index (AQI)}

Figure 6a-b clearly show less AQI during lockdown scenario and very high in the period of pre-lockdown. First time lockdown was declared on 24th march 2020 and extended up to the end of the May in different phases; however, we had also taken Janta curfew in our analysis which was on 22 March 2020. No activity was allowed during first lockdown while limited activities were allowed in the consecutive lockdown periods. Industrial operations, bus services, personal vehicles, and offices were closed and thus air was observed cleanest during lockdown period with decreased level of air pollutants. High mean and SD of AQI $(154 \pm 87.58)$ in pre-lock down scenario was observed. As compared to pre-lockdown, the AQI values $(94 \pm 46.5)$ were significantly less during lockdown; however, in post-lockdown scenario, a little difference was observed in average AQI with respect to lockdown period
(Table 6) probably due to the meteorological controls. A decrease of $39 \%$ in AQI was observed during lockdown from pre-lockdown scenario. However, the difference was less when compared with post-lockdown scenario.

\subsection{Excess Risk (ER\%) from Air Pollutants}

Total ER\% is estimated as sum of the ER\% of the five criteria pollutants including $\mathrm{PM}_{2.5}, \mathrm{PM}_{10}, \mathrm{SO}_{2}, \mathrm{NO}_{2}$ and $\mathrm{CO}$. During the analysis the minimum, maximum and mean of total ER\% was $10.2,32.8$, and 16.9 in pre-lockdown, $0.69,16.2$, and 6.7 during lockdown, and 0.67, 9.7, and 3.3 in post-lockdown, respectively, for whole study area (Figs. S6 and S7, supplementary material). During lockdown total ER\% was less as compared to pre-lockdown but higher from post-lockdown. Again it is to be mentioned that the post-lockdown period is mainly controlled by meteorological conditions and the concentration of pollutants remain low throughout the rainy season 
Table 5 Statistical values of parameters (in $\mu \mathrm{g} / \mathrm{m}^{3}$ except for CO which is measured in $\mathrm{mg} / \mathrm{m}^{3}$ ) in three scenario (Pre, during and PostLockdown)

\begin{tabular}{|c|c|c|c|c|c|c|c|}
\hline Lockdown scenario & Parameters & Total observations & Mean & Standard deviation & Minimum & Median & Maximum \\
\hline \multirow[t]{7}{*}{ Pre } & $\mathrm{PM}_{2.5}$ & 3688 & 71.12 & 44.95 & 3.42 & 59.53 & 475.22 \\
\hline & $\mathrm{PM}_{10}$ & 3474 & 139.29 & 72.77 & 16.19 & 121.72 & 591.96 \\
\hline & $\mathrm{NO}_{2}$ & 3571 & 28.17 & 20.88 & 1.16 & 23.64 & 247.49 \\
\hline & $\mathrm{NH}_{3}$ & 3042 & 33.31 & 23.97 & 0.57 & 28.20 & 310.40 \\
\hline & $\mathrm{CO}$ & 3633 & 1.00 & 0.65 & 0.01 & 0.82 & 5.23 \\
\hline & $\mathrm{O}_{3}$ & 3548 & 28.73 & 20.08 & 1.18 & 22.72 & 148.86 \\
\hline & $\mathrm{SO}_{2}$ & 3404 & 13.75 & 10.85 & 0.72 & 10.87 & 173.76 \\
\hline \multirow[t]{7}{*}{ During } & $\mathrm{PM}_{2.5}$ & 3242 & 38.67 & 20.14 & 3.93 & 34.64 & 156.26 \\
\hline & $\mathrm{PM}_{10}$ & 2979 & 96.06 & 54.86 & 10.68 & 82.58 & 348.35 \\
\hline & $\mathrm{NO}_{2}$ & 3027 & 17.29 & 13.49 & 0.28 & 14.46 & 151.16 \\
\hline & $\mathrm{NH}_{3}$ & 2545 & 25.45 & 17.88 & 2.49 & 22.38 & 288.12 \\
\hline & $\mathrm{CO}$ & 3167 & 0.66 & 0.46 & 0.01 & 0.53 & 5.38 \\
\hline & $\mathrm{O}_{3}$ & 3071 & 38.89 & 22.69 & 1.96 & 33.73 & 134.81 \\
\hline & $\mathrm{SO}_{2}$ & 2944 & 13.69 & 11.56 & 1.24 & 10.72 & 161.16 \\
\hline \multirow[t]{7}{*}{ Post } & $\mathrm{PM}_{2.5}$ & 1364 & 40.44 & 16.78 & 5.32 & 38.35 & 124.80 \\
\hline & $\mathrm{PM}_{10}$ & 1242 & 104.94 & 56.58 & 20.74 & 90.66 & 456.20 \\
\hline & $\mathrm{NO}_{2}$ & 1316 & 18.47 & 12.15 & 0.05 & 16.42 & 99.79 \\
\hline & $\mathrm{NH}_{3}$ & 1107 & 29.05 & 22.31 & 0.22 & 25.29 & 171.48 \\
\hline & $\mathrm{CO}$ & 1319 & 0.69 & 0.50 & 0.01 & 0.60 & 5.25 \\
\hline & $\mathrm{O}_{3}$ & 1310 & 38.55 & 22.09 & 1.20 & 33.69 & 125.83 \\
\hline & $\mathrm{SO}_{2}$ & 1243 & 12.7 & 8.9 & 0.52 & 8.93 & 85.36 \\
\hline
\end{tabular}

(Fig. 4a-c) and thus low ER\% was obtained (Fig. 7a, b). This study shows a very low ER\% during and post-lockdown (Fig. 7a) periods.

Statistical analysis of ER\% shows the significant decrease $(p=0.00)$ during lockdown and post-lockdown when compared with pre-lockdown. ER\% was high during lockdown as compared to post-lockdown because of the higher concentration of $\mathrm{PM}_{2.5}, \mathrm{SO}_{2}$, and $\mathrm{NO}_{2}$ in the month of May where the reduced pollution level were compensated by stubble burning incidences (Figure S5 supplementary material). It was observed that the ER\% is highly affected by $\mathrm{NO}_{2}$ and thus the change in the centration of $\mathrm{NO}_{2}$ (Figure S8, and Table A2, supplementary material) leads to the high ER\% in the last week of May. At the initial stage of lockdown, all activities including industrial, services, and vehicular movement were prohibited (Fig. 3 for vehicle movement obtained from TomTom GO Navigation Maps services of Apple) which leads to the reduction in air pollutants concentration and thus ER\%. But at the end of April and till May, 2020, the lockdown was relaxed, so the industrial and vehicular emissions were started increasing which was further supported by stubble burning in May 2020 (Fig. S5, supplementary material). However, the overall ER\% (mean) was high in pre- lockdown when compared with both during and postlockdown scenario (Fig. 7a, b).

Severe ER\% during pre-lockdown period was observed. The risk was high in some blocks of Haryana (Faridabad, Hathin, Palwal, Panipat, Ganaur, Sonipat, Hisar), and Delhi. Here, it is to be noted that the ER\% obtained through interpolation for the marginal blocks (i.e. blocks at the edge of study area boundary) may be erroneous due to statistical assumptions taken in interpolation and this is one of the limitation for the current study. However, the blocks identified inside the study area especially for Haryana, Punjab, and Delhi may be taken as the priority pollution management sites. Consistently high ER\% was observed in nearby regions of Delhi, NCR due to high vehicular pollution, industrial operations and poor wind circulation pattern (Fig. 7a, b). Main reason of high ER\% in the districts of Haryana including Panipat, Gurugram, Faridabad, and Hisar during pre-lockdown is industrial emissions (Singh \& Nanda et al., 2021c). Faridabad is one of the largest industrial cities in Haryana and thus showed high AQI values and high ER\%. Panipat also have many large and small industries such as thermal power plant, national fertilizer limited, oil refinery and other textile industries. Jindal Steel and power limited may be the main reason of 


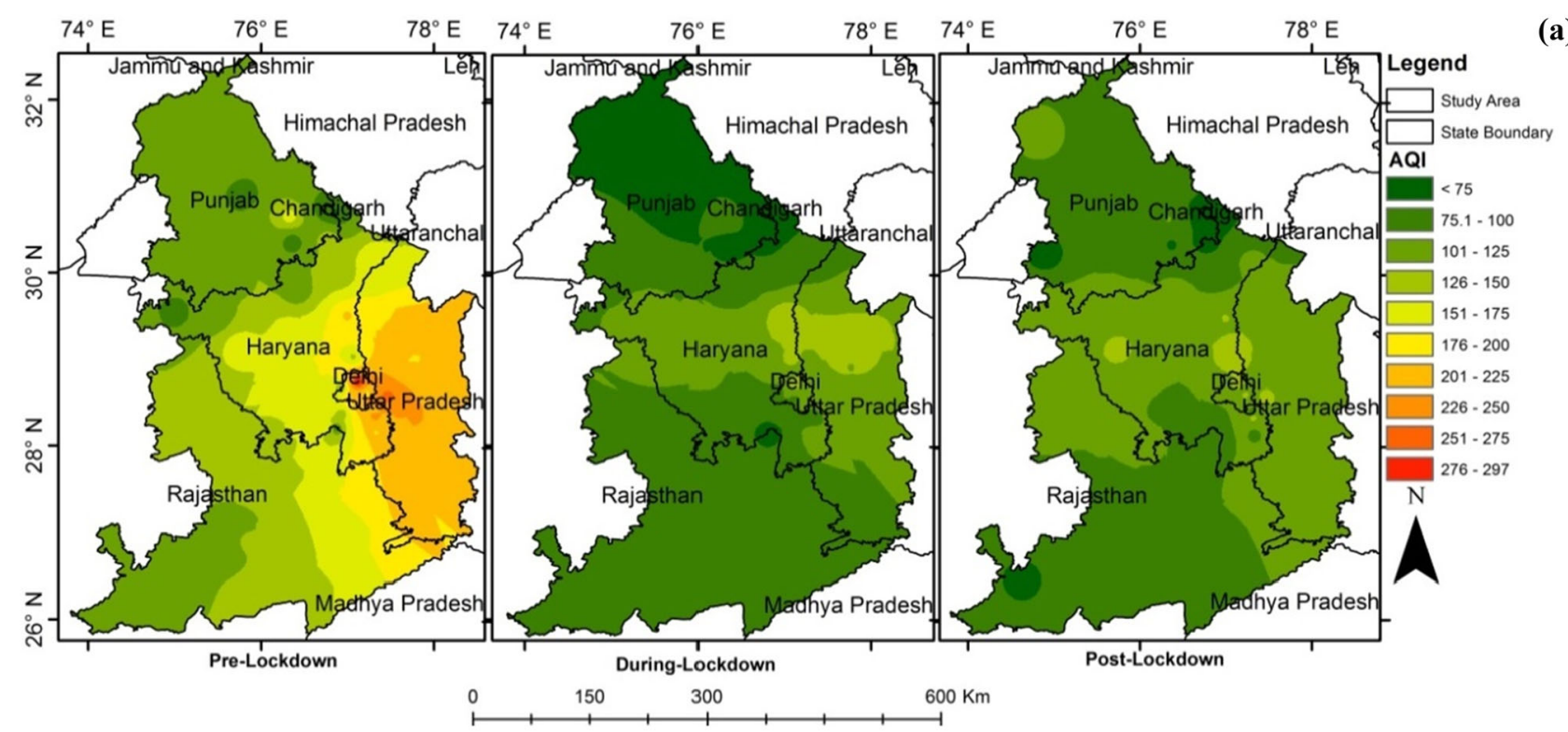

(a)

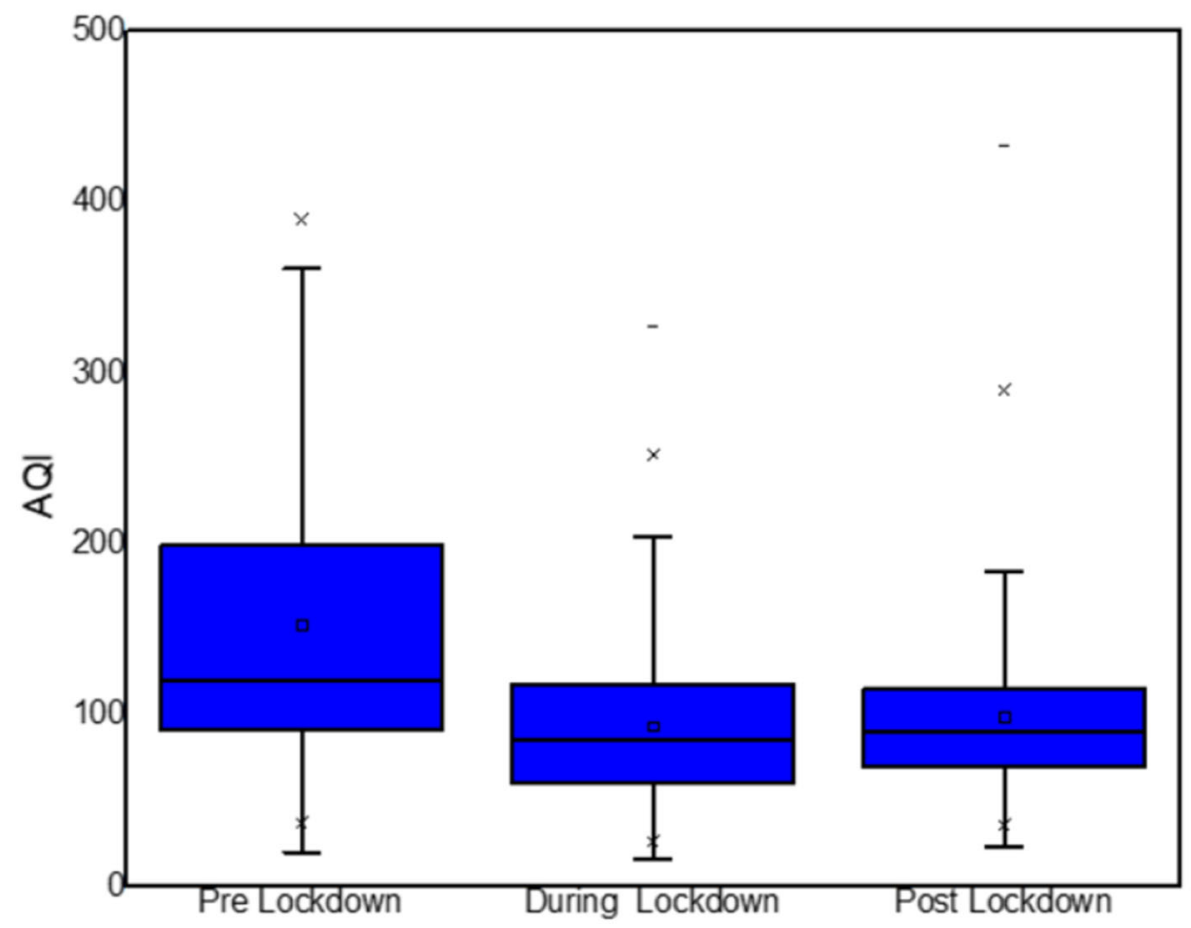

(b)

Fig. 6 Variation in Air quality index (AQI) in three scenarios- spatial a and statistical b

Table 6 Statistical analysis of air quality index (AQI) in different scenarios of lockdown

\begin{tabular}{lllllll}
\hline AQI & N total & Mean & SD & Minimum & Median & Maximum \\
\hline Pre-lockdown & 3731 & 154 & 87.58 & 20.4 & 121.03 & 602.45 \\
During lockdown & 3254 & 94 & 46.49 & 16.98 & 86.085 & 327.89 \\
Post-lockdown & 1415 & 100 & 47.07 & 24 & 91.13 & 432.75 \\
\hline
\end{tabular}



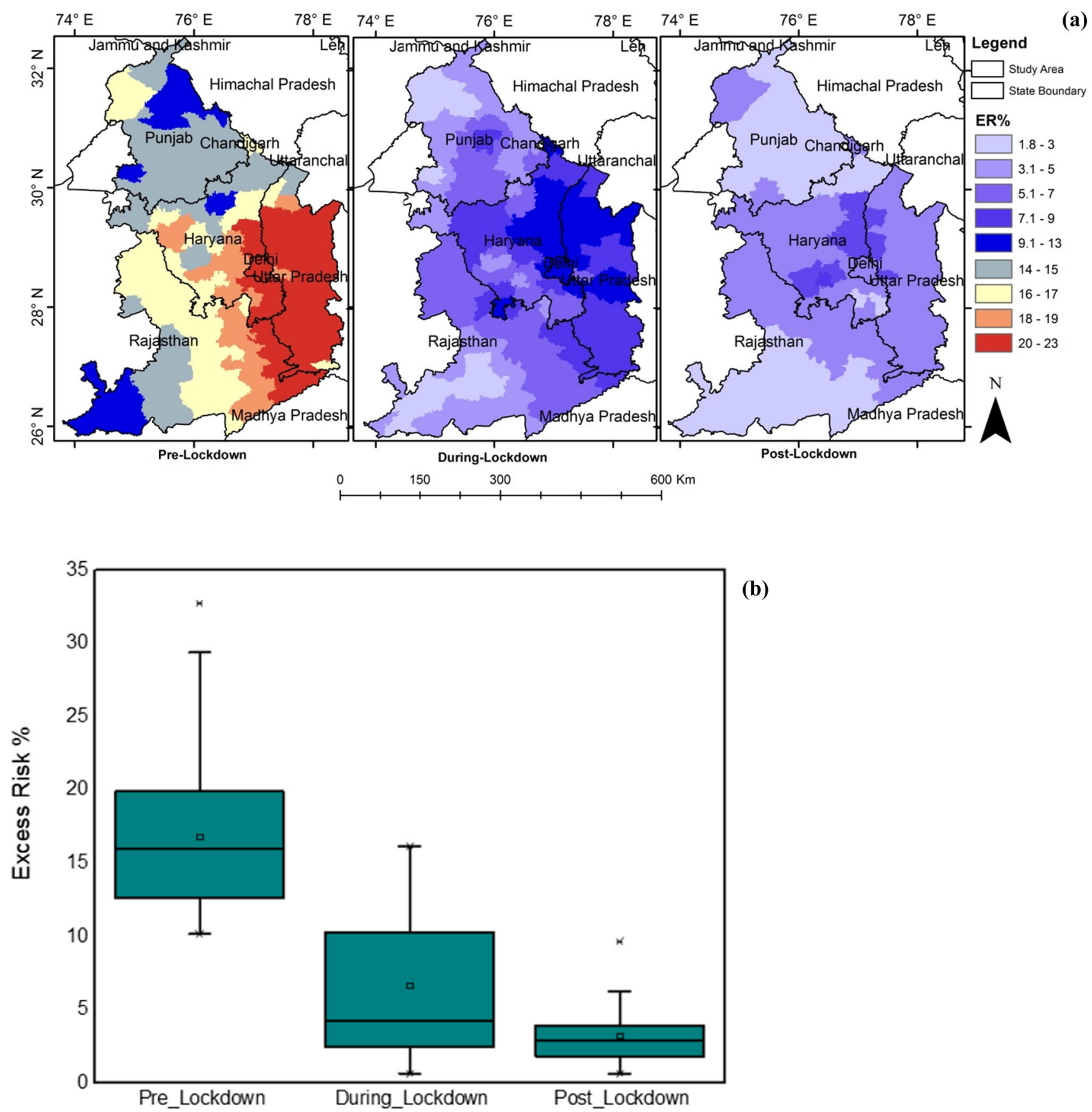

(b)

Fig. 7 ER\% variation in three scenarios-spatial (a), statistical (b)

the air pollution in Hisar district during winter (Singh \& Nanda et al., 2021c).

\section{Effect of Metrological Parameters on Air Pollutants}

In general the meteorological control on the pollutants concentration is seen during January-March 2020, November-December 2020, and January-April 2021 (Fig. 4a-1). It was also found that the metrological parameters have small change in the year 2020 when compared with 2019 and 2021 (Table A3, and Fig. S9-S12, supplementary material) but a huge change was observed in the concentration of pollutants especially during AprilMay 2020 (Singh \& Nanda et al., 2021c). Data for 2019 were used for the comparison due to its continuous availability. The changes in meteorological parameters for 2019 and 2020 were also found to be minimum (Figure S9 for temperature, S10 for RH, S11 for WS, and S12 for WD). Inter-correlation among various pollutants and 
metrological parameters was analysed for the year 2019 and 2020 and found significant correlation among them, but correlation $\left(r^{2}\right)$ were weak and lies below 0.36 in all the combinations (Tables 7, 8, respectively, for 2019 and 2020). With this weak correlation, our assumption that, the highly influential meteorological parameters will show high $r^{2}$ values and vice-versa, get accepted. This also showed that the meteorological parameters have less influence (i.e. weak $r^{2}$ ) on the change in the pollutants concentration during lockdown following Navinya et al. (2020) however, have potential to worsen the situation especially during winters. $\mathrm{PM}_{2.5}$ is significantly correlated with relative humidity in the year 2020 with $r=0.21$ whereas for the year 2019 the correlation was very less. However, from the analysis it was observed that the RH for the year 2020 (during lockdown period) is little higher as compared to the RH of the year 2019 (average difference 9.51\%, Table A3, supplementary material) but the $\mathrm{PM}_{2.5}$ get reduced significantly (average difference -15.79 ). This analysis clearly shows that there is less effect of meteorological parameters on the concentration of air pollutants (Tables 7 and 8) and thus the reduced anthropogenic activities may be responsible for the decrease in AQI in the year 2020 (Navinya et al., 2020). However, the influence of stubble burning during the last week of April and in the month of May cannot be denied seeing the pattern obtained in pollutant concentration (Fig. 4a-1) and fire events (Figures S5). It was also observed that the vehicle movement was very less during lockdown in 2020 and 2021 (Fig. 3) which also confirms the reduction in pollutant concentration, AQI values and ER\% in response to the reduced anthropogenic activities. However, the lockdown during May 2021 have not showed an effective reduction in the pollution level (Table 4) probably due to the relaxed measures of lockdown and compensation from stubble burning.

Other air pollutants have significant relation with metrological parameters such as relative humidity (RH), temperature, wind speed (WS) and wind direction (WD). When WS is high, pollutants get dispersed in the atmosphere and air quality gets improved; however, in our study area, the WS remains low (ranges between 1.70 and $2.9 \mathrm{~m} /$ s) during whole time period (January to June) taken to study the effect of lockdown. There were no major changes in the temperature (23.87 and 22.27 degree in 2019 and 2020, respectively) of the year 2019 and 2020 as presented in Fig. S9 and Table A3 (supplementary material). RH was little high in the year 2020 as shown in Figure S10 (Table A3 Supplementary material) and thus AQI was less. This shows the reciprocal relationship between AQI and RH following earlier study by Jayamurugan et al. (2013) who reported that the RH is highly correlated with PM which is considared as one of the important factor in deciding AQI of an area. Average WS was $1.8 \mathrm{~m} / \mathrm{s}$ in the year 2019 and $2.27 \mathrm{~m} / \mathrm{s}$ in the year 2020 and $2.00 \mathrm{~m} / \mathrm{s}$ in 2021 (supplementary material Fig. S11 and Table A3). The pattern of the WD was also found to be similar (SW direction) for the year 2019, 2020 and 2021 (supplementary material Fig. S12 and Table A3) following the findings of Sharma et al. (2020). Temperature, WS, and WD is almost same in all the three years but the RH is little high in 2020. This analysis clearly shows that the metrological conditions have less effect on the concentration of air pollutants or AQI over the region during lockdown period following earlier finding by Bhawre (2020) and Navinya et al. (2020). However, during rainy season and in winter season, the pollutant concetration is controled majorly by meteorology of the study area (Fig. 4a-1).

\section{Discussion}

This study explains the condition of the air quality in different states of northern India viz. Delhi, Punjab, Haryana, part of Eastern Uttar Pradesh, and part of Northern Rajasthan mainly during January 2020 to June 2021. Assessment of effects of lockdown on the pollutant concentration, AQI, and ER\% is the major focus of discussion, and done in three scenarios during 2020 including prelockdown, lockdown, and post-lockdown. $\mathrm{PM}_{2.5}, \mathrm{PM}_{10}$, $\mathrm{NO}_{2}, \mathrm{NH}_{3}$, and $\mathrm{CO}$ concentration was significantly decreased during lockdown when compare with pre-lockdown. $\mathrm{PM}_{2.5}, \mathrm{PM}_{10}, \mathrm{NO}_{2}, \mathrm{NH}_{3}$, and $\mathrm{CO}$ decreased by $46 \%$, $31 \%, 39 \%, 24 \%$, and $34 \%$ during lockdown scenario as compared to the pre-lockdown scenario. But $\mathrm{SO}_{2}$ concentration remained similar during lockdown and pre-lockdown may be due to the operational thermal power plants and other sources. $\mathrm{O}_{3}$ concentration was increased during lockdown due to the reduced vehicular movement (Figs. 3) and clear sky conditions.

The concentration of these parameters shows significant decrease because of lockdown similar to the earlier reported studies of Srivastava et al., (2020); Siddiqui et al., (2020); Sur et al., (2021) and Singh and Nanda et al. 2021c among others. However after that the concentration decreased significantly during the rainy season (except for $\mathrm{O}_{3}$ ) due to the settling of pollutants through rain and other meteorological controls (Fig. 4a-1). Overall scenario showed highest concentration in the pre-lockdown (including winters viz. January and February), low during lockdown (especially first lockdown during from 24 March to 14 April) and medium in post-lockdown (Tables 5 and 6). Little increase in the level of pollutants in May month is again due to crop stubble burning (Fig. S5) and allowed anthropogenic activities in relaxed lockdown. 


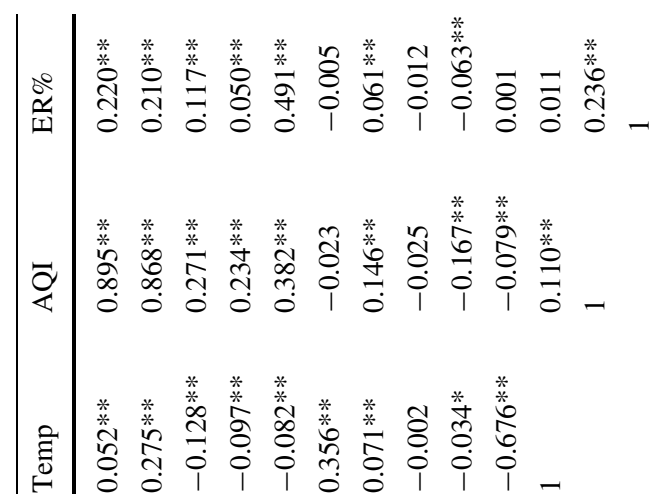

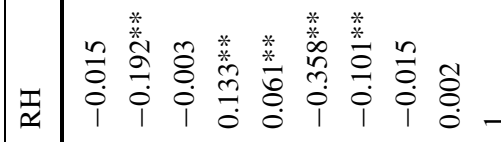

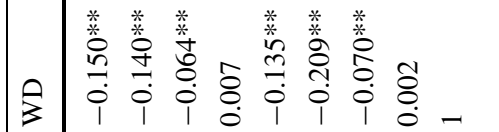

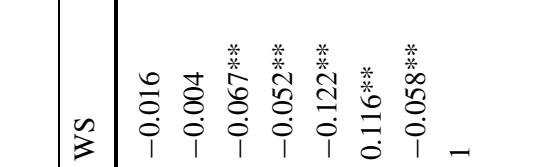

aे

药

岕

焉

$\ddot{\alpha}$

这

胥

$\frac{7}{6}$

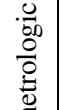

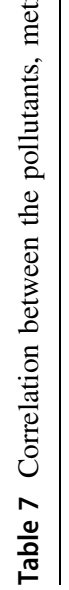

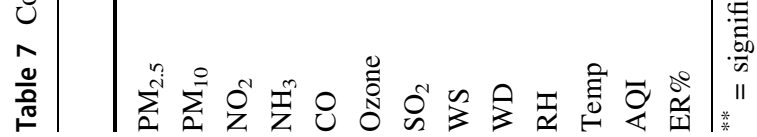

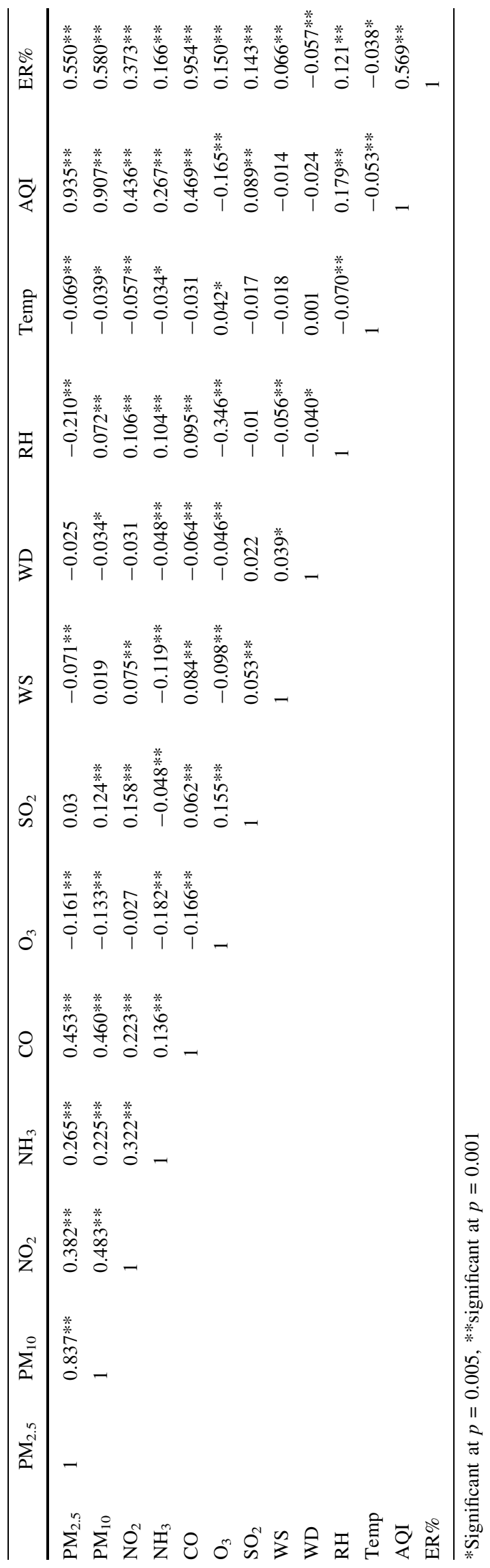


Findings of current study regarding the pollutants level were also compared with reference concentrations reported by other researchers for earlier years in the same region. The concentrations of pollutants (with respect to earlier concentration in bracket) like $\mathrm{PM}_{2.5}, \mathrm{PM}_{10}, \mathrm{NO}_{2}, \mathrm{CO}, \mathrm{O}_{3}$, and $\mathrm{SO}_{2}$ for 2020 were $53.39 \mu \mathrm{g} / \mathrm{m}^{3}\left(77 \mu \mathrm{g} / \mathrm{m}^{3}\right.$ in 2019), $117.01 \mu \mathrm{g} / \mathrm{m}^{3}\left(200 \mu \mathrm{g} / \mathrm{m}^{3}\right.$ in $\left.2017-2019\right), 22.39 \mu \mathrm{g} / \mathrm{m}^{3}$ (31.5 $\mu \mathrm{g} / \mathrm{m}^{3}$ in 2017$), 0.82 \mathrm{mg} / \mathrm{m}^{3}\left(1.1 \mathrm{mg} / \mathrm{m}^{3}\right.$ in 2019$)$, $34.28 \mu \mathrm{g} / \mathrm{m}^{3}$ (44 $\mu \mathrm{g} / \mathrm{m}^{3}$ in 2019$), 13.53 \mu \mathrm{g} / \mathrm{m}^{3}\left(15 \mu \mathrm{g} / \mathrm{m}^{3}\right.$ in 2019) (Sharma et al., 2020; Singh \& Nanda et al., 2021c). These figures clearly show the significant reduction in pollutants concentration in 2020 as compared to previous years because of lockdown. However, 2021 showed less effect of lockdown on the concentration of air pollutants (Table 4).

Average AQI during the lockdown period was 94 while in pre-lockdown and post-lockdown AQI was 154 and 100, respectively (Table 6). This reduction in AQI again confirmed the effect of lockdown on air quality improvement amid COVID-19. ER \% from the pollutants $\mathrm{PM}_{2.5}, \mathrm{PM}_{10}$, $\mathrm{SO}_{2}, \mathrm{NO}_{2}$, and $\mathrm{CO}$ were also calculated and mean and $\mathrm{SD}$ of total ER\% were $16.9 \pm 5.1,6.7 \pm 4.9$, and $3.3 \pm 2.0$ during pre-lockdown, lockdown and post-lockdown, respectively (Fig. 7a, b). Less ER\% post-lockdown is due to the variable magnitude of pollutant specific risk and their settling due to meteorological controls in the rainy season. This shows that the ER \% due to air pollution was lowered in lockdown scenario of 2020 amid COVID-19. Delhi was found to be highly polluted and thus very high ER \% was obtained.

Meteorological parameters were found to be less correlated with the pollutants in 2019 and 2020 and thus it may be said that there is very less influence of meteorology on the pollutants distribution over the study area during 2020 lockdown following the earlier findings of Navinya et al. (2020). Decrease in the mobility during the lockdown in 2021 was also seen; however, improvement in the pollution level was little less as compared to the improvement seen during 2020 lockdown.

\section{Conclusion}

Variation in the air pollutants $\left(\mathrm{PM}_{2.5}, \mathrm{PM}_{10}, \mathrm{NO}_{2}, \mathrm{CO}, \mathrm{O}_{3}\right.$, and $\mathrm{SO}_{2}$ ) and the effect of lockdown on criteria air pollutants, AQI and Excess Risk (ER \%) were examined in the Northern part of India taking ground-based data $(n=47)$ from January 2020 to June 2021 and GIS techniques. Meteorological data for 2019 were also used for the comparison due to the continuous availability. $\mathrm{PM}_{2.5}, \mathrm{PM}_{10}$, $\mathrm{NO}_{2}, \mathrm{CO}, \mathrm{O}_{3}$, and $\mathrm{SO}_{2}$ concentration were less in 2020 as compared to the concentration of these pollutants in the year 2019 and 2021. Daily pattern showed this phenomenon over the Delhi, Haryana, and Punjab where the highest pollution level was observed during October and November (stubble burning control), medium during winter months (December- February) and lowest during summer and monsoon. In pre-lockdown period $\mathrm{PM}_{2.5}$ concentration was greater $\left(71 \mu \mathrm{g} / \mathrm{m}^{3}\right)$ than CPCB standards $\left(40 \mu \mathrm{g} / \mathrm{m}^{3}\right)$ but during lockdown period the concentration was less $\left(38.7 \mu \mathrm{g} / \mathrm{m}^{3}\right)$ and falls in good air quality category. $\mathrm{PM}_{2.5}, \mathrm{PM}_{10}, \mathrm{NO}_{2}, \mathrm{NH}_{3}$, and $\mathrm{CO}$ decreased by $46 \%$, $31 \%, 39 \%, 24 \%$ and $34 \%$ in lockdown scenario as compared to the pre-lockdown scenario. $\mathrm{SO}_{2}$ concentration was not declined because of no restriction on coal-based thermal power plants and crop residue burning in this part of north India, considered as major source of $\mathrm{SO}_{2}$. Ozone $\left(\mathrm{O}_{3}\right)$ concentration was increased in lockdown period because of clear sky conditions in response to the reduction in pollutants concentration which resulted in to higher sunlight passing through atmosphere that resulted in to high rate of photo-reactions and thus high $\mathrm{O}_{3}$ formation. Decreasing trends of concentrations of pollutants just after lockdown in 2020 clearly show the effect of lockdown on air quality. However, lockdown during May 2021 was not effective much. AQI was in good to satisfactory category during lockdown.

The ER\% get reduced significantly in the year 2020 which may have possibly reduce the deaths due to air pollution and increased the life expectancy of inhabitants. However, assessing the exact increase in life expectancy is the subject of future research. Anthropogenic activities are the main causes of increasing the air pollutants in this region mainly in the months of May and OctoberNovember. The blocks (other than the blocks situated at the boundary) identified under high ER \% may be considered for air quality improvement and management sites. Meteorology has very less influence on pollutants concentration over the study area during the lockdown period. However, during monsoon and winter, the meteorology plays important role as seen in the daily data pattern of pollutants during the study period.

Supplementary Information The online version contains supplementary material available at https://doi.org/10.1007/s12524022-01520-z.

Acknowledgements $\mathrm{CPCB}$ is acknowledged for providing ground based air pollution data. Department of Environment and Climate Change, Haryana is highly acknowledged for funding this research work (programme code: P-31-1-1-3435-03-800-95-51).

Data Availability and Materials Data will be provided by the corresponding author on request.

\section{Declarations}

Conflict of interest No conflict of interest. 


\section{References}

Banarjee, T., Singh, S. B., \& Srivastava, R. K. (2011). Development and performance evaluation of statistical models correlating air pollution and metrological variables at Pantangar India. Atmospheric Research, 99, 505-517. https://doi.org/10.1016/j. atmosres.2010.12.003.

Bao, R., \& Zhang, A. (2020). Does lockdown reduce air pollution? Evidence from 44 cities in northern China. Science of the Total Environment, 731, 139052.

Bhawre P. (2020). Study of air quality index over indian region during lockdown research article study of air quality index over indian region during lockdown period COVID19. International Journal of Current Research https://doi.org/10.24941/ijcr.38710. 06.2020

Dantas, G., Siciliano, B., França, B. B., da Silva, C. M., \& Arbilla, G. (2020). The impact of COVID-19 partial lockdown on the air quality of the city of Rio de Janeiro Brazil. Science of the Total Environment, 729, 139085. https://doi.org/10.1016/j.scitotenv. 2020.139085

Dhaka, S. K., Kumar, V., Panwar, V., Dimri, A. P., Singh, N., Patra, P. K., \& Kajino, M. (2020). PM 2.5 diminution and haze events over Delhi during the COVID-19 lockdown period: An interplay between the baseline pollution and meteorology. Scientific reports, $10(1), 1-8$.

Filonchyk, M., Hurynovich, V., Yan, H., Gusev, A., \& Shpilevskaya, N. (2020). Impact Assessment of COVID-19 on Variations of $\mathrm{SO} 2, \mathrm{NO} 2, \mathrm{CO}$ and AOD over East China. Aerosol and Air Quality Research, 20(7), 1530-1540.

He, J., Gong, S., Yu, Y., Yu, L., Wu, L., Mao, H., \& Li, R. (2017). Air pollution characteristics and their relation to meteorological conditions during 2014-2015 in major Chinese cities. Environmental Pollution, 223, 484-496. https://doi.org/10.1016/j. envpol.2017.01.050

Huang, Y., Yan, Q., \& Zhang, C. (2018). Spatial-temporal distribution characteristics of in China in 2016. Journal of Geovisualization and Spatial Analysis, 2(2), 12.

Ilten, N., \& Selici, A. T. (2008). Investigating the impacts of some meteorological parameters on air pollution in Balikesir Turkey. Environmental Monitoring and Assessment, 140(1-3), 267-277. https://doi.org/10.1007/s10661-007-9865-1

Jayamurugan, R., Kumaravel, B., Palanivelraja, S., \& Chockalingam, M. P. (2013). Influence of temperature, relative humidity and seasonal variability on ambient air quality in a coastal urban area. International Journal of Atmospheric Sciences. https://doi. org/10.1155/2013/264046

Kanchan, K., Gorai, A. K., \& Goyal, P. (2016). A review on air quality indexing system. Asian Journal of Atmospheric Environment, 9(2), 101-113. https://doi.org/10.5572/ajae.2015.9.2. 101

Kant, Y., Mitra, D., \& Chauhan, P. (2020). Space-based observations on the impact of COVID-19-induced lockdown on aerosols over India. Current Science, 119(3), 539-544.

Kumar, A., Gupta, I., Brandt, J., Kumar, R., Dikshit, A. K., \& Patil, R. S. (2016). Air quality mapping using GIS and economic evaluation of health impact for Mumbai city, India. Journal of the Air and Waste Management Association, 66(5), 470-481. https://doi.org/10.1080/10962247.2016.1143887

Lal, P., Kumar, A., Kumar, S., Kumari, S., Saikia, P., Dayanandan, A., Adhikari, D., \& Khan, M. L. (2020). The dark cloud with a silver lining: Assessing the impact of the SARS COVID-19 pandemic on the global environment. Science of the Total Environment, 732, 139297. https://doi.org/10.1016/j.scitotenv. 2020.139297
Mahato, S., Pal, S., \& Ghosh, K. G. (2020). Effect of lockdown amid COVID-19 pandemic on air quality of the megacity Delhi India. Science of the Total Environment, 730, 139086.

Muhammad, S., Long, X., \& Salman, M. (2020). COVID-19 pandemic and environmental pollution: A blessing in disguise? Science of the Total Environment, 728, 138820.

Nakada, L. Y. K., \& Urban, R. C. (2020). COVID-19 pandemic: impacts on the air quality during the partial lockdown in São Paulo state Brazil. Science of the Total Environment, 730, 139087.

Navinya, C., Patidar, G., \& Phuleria, H. C. (2020). Examining effects of the COVID-19 national lockdown on ambient air quality across urban India. Aerosol and Air Quality Research, 20(8), 1759-1771. https://doi.org/10.4209/aaqr.2020.05.0256

Otmani, A., Benchrif, A., Tahri, M., Bounakhla, M., El Bouch, M., \& Krombi, M. H. (2020). Impact of Covid-19 lockdown on PM10, $\mathrm{SO} 2$ and NO2 concentrations in Salé City (Morocco). Science of the Total Environment, 735, 139541.

Pathakoti, M., Muppalla, A., Hazra, S., Dangeti, M., Shekhar, R., Jella, S., Mullapudi, S. S., Andugulapati, P., \& Vijayasundaram, U. (2020). An assessment of the impact of a nation-wide lockdown on air pollution-A remote sensing perspective over India. Atmospheric Chemistry and Physics. https://doi.org/10. 5194/acp-2020-621

Ranjan, A. K., Patra, A. K., \& Gorai, A. K. (2020). Effect of lockdown due to SARS COVID-19 on aerosol optical depth (AOD) over urban and mining regions in India. Science of the Total Environment, 745, 141024.

Sharma A. (2020). Invest India, 2020. What constitutes essential services during lockdown? https://www.investindia.gov.in/teamindia-blogs/what-constitutes-essential-services-during-lockdown (accessed on 7 August 2020).

Sharma, S., Zhang, M., Gao, J., Zhang, H., \& Kota, S. H. (2020). Effect of restricted emissions during COVID-19 on air quality in India. Science of the Total Environment, 728, 138878. https:// doi.org/10.1016/j.scitotenv.2020.138878

Shehzad, K., Sarfraz, M., \& Shah, S. G. M. (2020). The impact of COVID-19 as a necessary evil on air pollution in India during the lockdown. Environmental Pollution, 266, 115080. https://doi. org/10.1016/j.envpol.2020.115080

Siddiqui, A., Halder, S., Chauhan, P., \& Kumar, P. (2020). COVID19 Pandemic and city-level nitrogen dioxide (NO2) reduction for urban centres of India. Journal of the Indian Society of Remote Sensing, 48(7), 999-1006. https://doi.org/10.1007/s12524-02001130-7

Singh, D., \& Nanda, C. (2020). Aerosol optical depth (AOD) variation over haryana due to lockdown amid Covid-19 as an indicator of air quality. In 2020 IEEE India GEOSCIENCE and Remote Sensing Symposium (InGARSS) pp. 170-172. IEEE. https://doi.org/10.1109/InGARSS48198.2020.9358971.

Singh, D., Dahiya, M., Kumar, R., \& Nanda, C. (2021a). Sensors and systems for air quality assessment monitoring and management: A review. Journal of Environmental Management, 289, 112510.

Singh, D., Kundu, N., \& Ghosh, S. (2021b). Mapping rice residues burning and generated pollutants using Sentinel-2 data over northern part of India. Remote Sensing Applications: Society and Environment, 22, 100486.

Singh, D., Nanda, C., \& Dahiya, M. (2021c). State of air pollutants and related health risk over Haryana India as viewed from satellite platform in COVID-19 lockdown scenario. Spatial Information Research. https://doi.org/10.1007/s41324-02100410-9

Srivastava, S., Kumar, A., Bauddh, K., Gautam, A. S., \& Kumar, S. (2020). 21-Day Lockdown in India Dramatically Reduced Air Pollution Indices in Lucknow and New Delhi, India. Bulletin of 
Environmental Contamination and Toxicology. https://doi.org/ 10.1007/s00128-020-02895-w.

Sur, K., Verma, V. K., \& Pateriya, B. (2021). Variation of tropospheric NO2 over Indo-Gangetic plain during COVID-19 outbreak in India. Spatial Information Research. https://doi.org/ 10.1007/s41324-021-00399-1.

Tobías, A., Carnerero, C., Reche, C., Massagué, J., Via, M., Minguillón, M. C., Alastuey, A., \& Querol, X. (2020). Changes in air quality during the lockdown in Barcelona (Spain) one month into the SARS-CoV-2 epidemic. Science of the Total Environment, 726, 138540. https://doi.org/10.1016/j.scitotenv. 2020.138540
Wai, T., Wai, W., Tam, S., Tak, I., Yu, S., Kai, A., Lau, H., Wing, S., \& Wong, A. H. S. (2013). Developing a risk-based air quality health index. Atmospheric Environment, 76, 52-58. https://doi. org/10.1016/j.atmosenv.2012.06.071

World Health Organisation (WHO). (2021). WHO Coronavirus (COVID-19) Dashboard, available at https://covid19.who.int/ accessed on 18 Jan 2022.

Publisher's Note Springer Nature remains neutral with regard to jurisdictional claims in published maps and institutional affiliations. 